\section{Nano-ZnO leads to tubulin macrotube assembly and actin bundling, triggering cytoskeletal catastrophe and cell necrosis}

Lorena García-Heviaa , Rafael Valiente ${ }^{\mathrm{ab}}$, Rosa Martín-Rodríguez ${ }^{\mathrm{ac}}$, Carlos Renero-Lecuna ${ }^{\mathrm{ab}}$, Jesús González $^{\text {ad }}$, Lidia Rodríguez-Fernándeze ${ }^{\mathrm{e}}$ Fernando Aguadod, Juan C. Villegas ${ }^{\mathrm{a}}$ and Mónica L. Fanarraga $^{a}$

Zinc is a crucial element in biology that plays chief catalytic, structural and protein regulatory roles. Excess cytoplasmic Zinc is toxic to the cells so there are cell-entry and intracellular buffering mechanisms that control intracellular Zinc disponibility. Tubulin and actin are two Zinc-scavenging proteins that are essential components of the cellular cytoskeleton implicated in cell division, migration and cellular architecture maintenance.

Here we demonstrate how exposure to different $\mathrm{ZnO}$ nanostructures, namely $\mathrm{ZnO}$ commercial nanoparticles and custommade $\mathrm{ZnO}$ nanowires, produce acute cytotoxic effects in human keratinocytes (HaCat) and epithelial cells (HeLa) triggering a dose-dependent cell retraction and collapse. We show how engulfed ZnO nanoparticles dissolve intracellularly, triggering actin filament bundling and structural changes in microtubules, transforming these highly dynamic $24 \mathrm{~nm}$ diameter polymers into rigid macrotubes of tubulin, severely affecting cell proliferation and survival. Our results demonstrate that nano-ZnO causes an acute cytoskeletal collapse that triggers necrosis, followed by a late reactive oxygen species (ROS)-dependent apoptotic process.

\title{
Introduction
}

Nanomaterials represent a major technological advance and their applications in everyday products raise many safety questions. In particular, the extended use of nano-ZnO as an additive in numerous human consumption products has opened a controversy regarding the biological effects of these nanoparticles.

Bulk $\mathrm{ZnO}$ is a well-known wide bandgap semiconductor employed in countless applications. ZnO micrometric particles have been used in cosmetics and sunscreens for many years and have been catalogued as innocuous due to their low water solubility. However, since most of the available toxicity tests are not specifically validated for nanomaterials, the incorporation of nano-sized ZnO has introduced many new variables regarding the biocompatibility after topical delivery of ZnO. Among others, the effect of these nanomaterials after exposure to UV light or when applied in damaged skin or mucosal membranes remains unclear. ${ }^{1-3}$

The $\mathrm{ZnO}$ particle size is critical in terms of toxicity due to different reasons. First in terms of solubility, since nanomaterials expose a huge surface to the surrounding solvent. ${ }^{4-6}$ Second, because ZnO nanoparticles with diameter smaller than 150 nm can cross the upper skin layer ${ }^{7}$ accumulating in the epidermis and dermis, ${ }^{8,9}$ releasing small amounts of Zinc to the blood that can be detected many weeks after topical administration. ${ }^{10,11}$ Moreover, $\mathrm{ZnO}$ dissolution has been reported to increase when exposed to biological solvents ${ }^{4,12-14}$ and after exposure to UV irradiation. ${ }^{1-3,15-17}$

Despite these facts, relatively high extracellular $\mathrm{Zn}^{2+}$ levels do not produce significant cytotoxic effects. ${ }^{18-20}$. Cells require small amounts of $\mathrm{Zn}^{2+}$ for distinct intracellular biological processes so there are tightly controlled and saturable mechanisms in the cell membrane ${ }^{21,22}$ that maintain the cytoplasmic Zinc homeostasis typically at $10 \mathrm{ng} / \mathrm{L} .{ }^{23}$ These precise mechanisms are circumvented when nano-ZnO is endocytosed, increasing the intracellular Zinc levels up to $400 \% .{ }^{13}$ Hence, although approximately $10 \%$ of the entire human proteome encodes $\mathrm{Zn}^{2+}$ ion scavenger proteins, ${ }^{24}$ these levels are far from tolerable and trigger toxicity.

Tubulin ${ }^{25,26}$ and actin $^{27}$ contain several $\mathrm{Zn}^{2+}$-binding sites. These two intracellular cytoskeleton proteins -key players in cell division, cell migration and the maintenance of the cellular architecture-, assemble highly dynamic nano-polymers known as microtubules and actin microfilaments, respectively. ${ }^{28}$ In cells such as neurons, these proteins can represent almost $1 / 3$ of the total soluble protein contents ${ }^{29}$ and thus, both tubulin and actin are important in Zinc homeostasis.

In the archived literature there is little information regarding Zinc binding effects on actin structure or function. ${ }^{27}$ On the contrary, many Zinc binding sites have already been mapped on the tubulin molecule. ${ }^{26,30,31}$ Remarkably, tubulin polymerized in vitro in the presence of Zinc assembles aberrant tubulin microtubules that change from $24 \mathrm{~nm}$ diameter nanotubes to large macrotubes, or even flat aberrant tubulin sheets. ${ }^{25,30,32,33}$ The reason is that Zinc binding triggers a structural twist in the tubulin molecule, broadening the lateral protofilamentprotofilament binding angle that favours the assembly of these structures in vitro. ${ }^{34,35}$

In this work we investigate the biological effects of nano-sized $\mathrm{ZnO}$ in human epithelial and endothelial cells, and demonstrate for the first time how nano-ZnO dissolution has a direct deleterious effect on the cellular cytoskeleton, leading to proliferative defects and acute cytotoxicity. By comparison with $\mathrm{TiO}_{2}$ anatase nanoparticles of similar sizes and shapes or $\mathrm{ZnO}$ nanoparticles coated with a thin shell of $\mathrm{SiO}_{2}$ we demonstrate that toxic effects are directly related to intracellular dissolution of $\mathrm{ZnO}$. 


\section{Experimental}

\section{Nanomaterials, nanoparticle functionalization and coating with $\mathrm{SiO}_{2}$}

Three type of nanomaterials were used: (i) commercially ZnO nanoparticles Z-COTE ${ }^{\circledR}$ (BASF Chemical Company)(Fig. 1) and Nanox (Elementis), (ii) $\mathrm{TiO}_{2}$ nanoparticles (BASF Chemical Company) (Fig. S1A), and (iii) in-house synthetized ZnO nanowires. ${ }^{36}$ Commercial ZnO nanoparticles were coated with $\mathrm{SiO}_{2}$ as described by Stöber. ${ }^{37}$ Briefly, $150 \mathrm{mg}$ of $\mathrm{ZnO}$ nanoparticles were dispersed in isopropyl alcohol by sonication. Deionized water $(4.5 \mathrm{~mL})$ and hydrous ammonia $(6 \mathrm{~mL})$ were added dropwise under stirring at $50 \cong \mathrm{C}$ for 10 min. Tetraethylorthosilicate (TEOS) $(150 \mu \mathrm{L})$ were incorporated in the mixture that was stirred in dark conditions at $50 \cong \mathrm{C}$ for $1 \mathrm{~h}$. Particles were washed in deionized water by repeated cycle of centrifugation and resuspension.

\section{Transmission Electron Microscopy (TEM)}

Morphological characterization of the $\mathrm{ZnO}$ and $\mathrm{TiO}_{2}$ nanoparticles, $\mathrm{ZnO}$ nanowires and $\mathrm{SiO}_{2}$-coated $\mathrm{ZnO}$ was performed in a JEOL JEM 2100 transmission electron microscope operating at $200 \mathrm{kV}$. Nanomaterials were suspended in ethanol and adsorbed onto 400 mesh carboncoated copper grids. Electron microscopy on cells was performed on $70 \mathrm{~nm}$ Araldite sections of pellets of cells fixed with $1 \%$ glutaraldehyde in $0.12 \mathrm{M}$ phosphate buffer, washed in $0.12 \mathrm{M}$ phosphate buffer, post-fixed in $1 \%$ buffered osmium tetroxide, dehydrated in a graded acetone series, embedded in Araldite, sectioned and stained with lead citrate and uranyl acetate. These samples were observed using a JEOL JEM 1011 microscope.

\section{X-ray Diffraction (XRD)}

Structural characterisation of $\mathrm{ZnO}$ and $\mathrm{TiO}_{2}$ nanoparticles was carried out using a Bruker D8 Advance diffractometer equipped with a Cu tube, a graphite monochromator $(\langle\lambda\rangle=1.5418 \AA$ ) and a scintillation detector in Bragg-Brentano geometry with fixed slit configuration (divergence

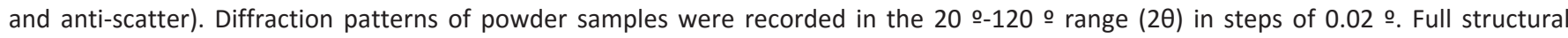
characterisation through the Rietveld method was performed with TOPAS software. Average particle size was estimated by the double-Voigt method (size and strain) ${ }^{38}$ using the fundamental parameters approach ${ }^{39}$ and standard measurement (LaB ${ }_{6}$ ) for modelling and convoluting the instrumental function.

\section{Cell Culture, immunostaining, confocal microscopy and live cell imaging}

HaCat (immortalized human keratinocytes) and HeLa cells (immortalized human cervical cancer cells) were used for the study. HaCat cells were kindly provided by Dr. Jorcano from the CIEMAT (Spain) and Dr. Quintanilla from the Institute of Biomedical Research Alberto Sols (CSIC-

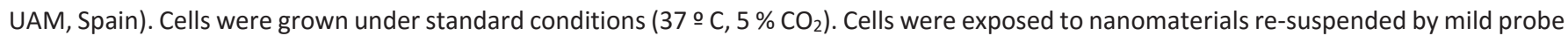
sonication in standard tissue culture medium containing $10 \%$ serum. Immunostaining was performed on cells fixed in $4 \%$ paraformaldehyde. Antibodies used were anti- $\alpha$-tubulin (B512) (Sigma-Aldrich) combined with a secondary goat anti-mouse IgG antibody conjugated with Alexa Fluor 488 (Molecular Probes, Invitrogen). Actin was stained with phalloidin-tetramethylrhodamine B isothiocyanate and DNA with Hoechst dye (Bisbenzimide) (all from Sigma-Aldrich). Live cell necrosis time-lapse microscopy (Video S1) was performed on cells exposed to different $\mathrm{ZnO}$ nanoparticle dosages and Propidium lodide (PI) that were filmed in a Nikon-Ti microscope live-cell station during $24 \mathrm{~h}$. Confocal microscopy images were obtained with a Nikon A1R confocal microscope and processed with the NIS-Elements Advanced Research software.

\section{Determination of apoptosis, necrosis, cell cycle analysis and reactive oxygen species (ROS)}

The dynamics of necrosis versus apoptosis was investigated using two different approaches. A classical approach, where necrotic cells were identified and quantified using a trypan blue assay $24,48,72$ and $96 \mathrm{~h}$ post-exposure to $\mathrm{ZnO}$, and apoptosis was investigated by flow cytometric analysis of ca. 10.000 cells stained with Hoechst, quantifying the fractional DNA content ("sub-G1/G0" peak) (Fig. S2). A second complementary approach permitted the simultaneous determination of necrosis, apoptosis, and the proliferative status of the cell population using a commercial kit (Immunostep, Ref.: ANXVKPE-100T) at different time points (Figs. 2E, S3). Three cell populations were detected as follows: (i) unstained cells representing viable cells (shown in green), (ii) Annexin V (+) / PI (-) representing apoptotic cells (red) and (iii) Annexin V (+) / PI (+) representing necrotic cells (blue). Original flow cytometric graphs are included as supplementary information (Fig S3). Intracellular reactive oxygen species (ROS) detection was performed at different time points by flow cytometry quantification of ca.10.000 cells stained with Dihydroethidium (DHE) (Sigma-Aldrich) (Fig S6). Flow cytometry experiments were performed using a Becton Dickinson FACS Cantoll equipment. Data were analysed using the FACS Diva software (Becton Dickinson, NJ, USA). 


\section{Intracellular nanoparticle analysis}

Cells exposed to nanoparticles were thoroughly washed by centrifugation to remove superficial materials and were lysed in a hypotonic physiological ( $\mathrm{pH}$ 7.4) buffer containing Triton X-100. Pelleted material including the intracellular nanoparticles was resuspended in ethanol and was heated at $400 \cong \mathrm{C}$ for several hours to remove organic material. Randomly obtained TEM micrographs of $128 \mathrm{ZnO}$ crystals were used to measure the longest nanoparticle axis using the IMAGE J software. KaleidaGraph and R software packages were used for histogram plotting and statistical analysis, respectively. All statistical tests, namely Levene, Shapiro-Wilk and Kruskal Wallis ANOVA were performed at the 0.05 significance level. To choose the most appropriate statistical test, we checked whether experimental data fulfil the conditions assumed by the parametric tests, namely homoscedasticity (similarity of variances) and normality. If the data do not fulfil these assumptions, nonparametric tests were used. Homoscedasticity of our experimental data was proved by the Levene's test ( $p$-value $=0.2162, \alpha=0.05$ ), while the normal distribution condition was rejected on the base of the results of the Shapiro-Wilk test ( $p$-values= 4.25.10-4, 0.0453 and 3.76.10-6, respectively, $\alpha=0.05$ ). These data did not satisfy the assumptions of parametric tests and thus, a non-parametric Kruskal Wallis ANOVA test was performed.

\section{Micro-Raman spectroscopy}

Raman spectroscopy was performed on live HaCat cells exposed to $\mathrm{ZnO}$ nanoparticles and grown on the microscope stage for $5 \mathrm{~h}$. The unpolarized micro-Raman spectra were taken with a confocal microscope coupled to a Horiba T64000 triple spectrometer in the backscattering geometry, using the $647 \mathrm{~nm}$ line of $\mathrm{Ar}^{+}-\mathrm{Kr}^{+}$laser (Coherent Innova Spectrum 70C) and a nitrogen cooled CCD (Jobin-Yvon Symphony). Intracellular spectra were obtained with the laser beam focused to $1 \mu \mathrm{m}$ spot with a $100 \mathrm{x}$ objective and kept the power on the sample below $2 \mathrm{~mW}$ to avoid laser-heating effects. The focal point was maintained in the time-lapsed spectra (Fig. S4B): Spectrograms obtained 3 and $5 \mathrm{~h}$ post incubation with $\mathrm{ZnO}$ are shown. With our experimental conditions, laser wavelength $\lambda=647 \mathrm{~nm}$ and a microscope objective of $100 \mathrm{X}$ with a numerical aperture of NA $=0.85$, we obtained a focal spot of $0.93 \mu \mathrm{m} 0.93 \mu \mathrm{m}(1.22 \lambda / \mathrm{NA})$ and resolution depth of about $0.9 \mu \mathrm{m}(\lambda / \mathrm{NA} 2)$..

\section{Results}

\section{ZnO nanoparticle characterisation}

Commercial ZnO nanoparticles (Z-COTE ${ }^{\circledR}$ ) were characterised by $\mathrm{x}$-ray diffraction (XRD). $\mathrm{F}$ ig. $1 \mathrm{~A}$ shows the Rietveld refinement of the nanoZnO XRD pattern. Only reflections corresponding to the main phase (hexagonal Zincite structure, space group $P 6_{3} m c$ ) were observed, and no secondary phases were detected within the experimental resolution. Refined lattice parameters, atomic coordinates and isotropic displacement parameters were in good agreement with values reported previously. ${ }^{40}$ An estimation of average particle size was obtained through the double-Voigt method from the whole powder pattern fitting. ${ }^{38}$ The calculated average crystallite size parameter was $\left\langle L_{\text {vol }}\right\rangle=$ $86 \pm 3 \mathrm{~nm}$. This is very similar to the value determined for $\mathrm{TiO}_{2}$ nanoparticles used in this study (Anatase phase, space group $14_{1} / \mathrm{amd}^{41}$ ): $\left\langle\mathrm{L}_{\text {Vol }}\right\rangle=88 \pm 5 \mathrm{~nm}$. Typically, this parameter could be considered an effective high limit in the particle size distribution, being larger than size determined by TEM, which is closer to the distribution mean value. Assuming single domains and cubic shape for the particles, we estimated an average grain size of $119 \mathrm{~nm}$ for the nano-ZnO sample. ${ }^{42} \mathrm{Fig} .1 \mathrm{~B}$ shows representative TEM images of the employed ZnO nanoparticles where hexagonal prisms, hexagonal plates and hexagonal rods of a broad range of dimensions were shown.

\section{ZnO nanoparticles trigger dose-dependent cytotoxic effects in human keratinocytes and epithelial cells}

Both, human skin keratinocytes (HaCat) and human epithelial cells (HeLa) were exposed to different concentrations of ZnO nanoparticles resuspended in standard cell culture medium. As previously reported, ${ }^{43,44}$ incubation of these cells with $\mathrm{ZnO}$ nanoparticles significantly reduced cell viability in a time and concentration dependent manner. Specifically, dosages above 30 $\mathrm{\mu g} / \mathrm{mL}$ of ZnO nanoparticles triggered a massive cell retraction in most cells in few hours, while dosages of $15 \mu \mathrm{g} / \mathrm{mL} \mathrm{produced} \mathrm{no}$ noticeable cell changes. Identical viability was observed for both types of cells (Fig.2A). The observed cell collapse was concomitant to cytoplasmic membrane permeabilisation, as observed in $24 \mathrm{~h}$ time-lapsed videos of cells exposed to ZnO (red cells, Fig. 2A, Video S1). Remarkably, undistinguishable cytotoxic effects were also observed in cells exposed to ZnO nanowires (Fig. 2B). ${ }^{36}$ Cell death due to unspecific bio-synthetic interactions was discarded exposing cells to morphologically similar $\mathrm{TiO}_{2}$ nanoparticles (Fig. S1A). Contrary to $\mathrm{ZnO}$, and despite massive intracellular $\mathrm{TiO}_{2}$ nanoparticle engulfment, dosages of up to $100 \mu \mathrm{g} / \mathrm{mL}$ did not trigger cell collapse in these cell models even $40 \mathrm{~h}$ after exposure.

Finally, cytotoxicity due to extracellular ZnO-nanoparticle dissolution in the culture medium was investigated using two different approaches, (i) exposing cells to filtered medium that had been incubated during $24 \mathrm{~h}$ at 37 o $\mathrm{C}$ with $100 \mathrm{\mu g} / \mathrm{mL} \mathrm{ZnO-nanoparticles,}$ and (ii), culturing cells in $100 \mu \mathrm{g} / \mathrm{mL} \mathrm{ZnCl}_{2}$ in the medium. In either case, no evident signs of cell collapse or cytotoxicity were 
observed $24 \mathrm{~h}$ after cell exposure. These findings support that (i) nano-ZnO cell uptake is critical to trigger cell collapse and cytotoxic effects -as previously reported by other authors-, ${ }^{13,19,45,46}$ (ii) the cytotoxic effect is triggered regardless the structure or shape of the nano-ZnO, and (iii), the toxicity cannot be attributed to unspecific interactions.

\section{$\mathrm{ZnO}$ nanoparticles produce cell death by both, necrosis and apoptosis}

In response to any external insult, cells can undergo apoptosis and necrosis or both, independently, sequentially or simultaneously. ${ }^{47}$ The main gross differences between these two types of cell death are (i) the integrity of the cytoplasmic membrane and (ii) the fragmentation of nuclear DNA, both typical of apoptosis. ZnO cytotoxicity has been broadly reported in the literature. Most studies demonstrate how nano-ZnO provokes elevated ROS stress, mitochondrial superoxide formation and depolarization of mitochondrial membrane finally leading to apoptosis days after treatment. ${ }^{14,19,43,48-50}$ Yet there are also studies in neurons that suggest the possibility of nano-ZnO triggering an early necrotic processes. ${ }^{51}$

Our results show early cell death events characterised by membrane permeabilisation (Fig. 2A, Video S1) and this feature being characteristic of necrosis. ${ }^{52}$ To study further the chronology of the observed cell death processes we have performed two complementary studies. On one hand we have investigated cell necrosis performing a standard membrane permeabilisation assays using trypan blue, complemented with a flow cytometric analysis of DNA fragmentation to determine apoptosis (Figs. 2D, S2). And on the other, we have employed a commercial kit based on series of well-established cell indicators of necrosis and apoptosis. Apoptotic cells are identified by the presence of Annexin $V$ on their surface (Fig. 2E, red), while necrotic cells are only stained for non-vital dyes (propidium iodine)(blue). Under our experimental conditions, both independent studies (Figs. 2D-2E) revealed that cultures exposed to $30 \mathrm{\mu g} / \mathrm{mL} \mathrm{ZnO}$ nanoparticles during $24 \mathrm{~h}$ displayed mostly necrotic cells (blue). Longer exposure times produced massive necrosis in the cultures (Fig. S3). Control cells exposed to nano- $\mathrm{TiO}_{2}$ were virtually unaffected $24 \mathrm{~h}$ after exposure to $30 \mu \mathrm{g} / \mathrm{mL}$ of nanoparticles in the culture medium (Fig. 2E, bottom). Summarizing, these assays endorse the hypothesis that dosages of $30 \mu \mathrm{g} / \mathrm{mL}$ or more of nano-ZnO trigger an early necrotic cell death process $3-5 \mathrm{~h}$ after cell exposure.

\section{Intracellular ZnO nanoparticle dissolution is concomitant to cell collapse}

It is broadly admitted that, following endocytosis or phagocytosis, ZnO-nanoparticles are included in endosomes that subsequently fuse to lysosomes. ${ }^{13,18,19,49,50}$ The endo-lysosomes work as the digestive system of the cell and exhibit a low $\mathrm{pH}$ that can dissolve different shapes of nano-ZnO particles in less than $24 \mathrm{~h}$ in vitro and in vivo. ${ }^{13,18,19,53,54}$ Archived literature also shows how in macrophages, intracellular $\mathrm{ZnO}$ dissolution releases massive amounts of $\mathrm{Zn}^{2+}$ ions that escape the endo-lysosome compartment into the cytosol. ${ }^{13}$ However, ZnO nanoparticle dissolution in macrophages cannot be directly extrapolated to other cells, such as keratinocytes or epithelial cells that do not have this highly specialized lysosomal degradative potential.

Consequently, we have investigated intracellular $\mathrm{ZnO}$ nanoparticle dissolution in HaCat cells. For the study, we have performed two different approaches. The first, approach consisted on isolating $\mathrm{ZnO}$ nanoparticles from inside HaCat cells $5 \mathrm{~h}$ after engulfment. Intracellular nanoparticles were obtained from cultured cells after thorough washing and rupture with buffer containing detergent. Organic material was removed at 400 C (see the experimental section). Isolated nanoparticles were examined and identified by electron-microscopy and were compared to control nanoparticles exposed to cell culture medium devoid of cells also incubated at 37 o $\mathrm{C}$ for $5 \mathrm{~h}$ (Fig. 3A, 3B). To confirm the chemical nature of the intracellular nanomaterials, and to discard possible solid contaminants, we used energy-dispersive X-ray spectroscopy (EDX) (Fig. S4A). Zn and O were detected together with Cu and C signals arising from the carbon coated copper grid. Fig. 3A demonstrate how the ZnO nanocrystals incubated in cell medium show no longer well-defined crystal facets and had somewhat reduced the average particle size compared to the pristine nanoparticles (Fig. 1B), thus suggesting partial nanoparticle dissolution. On the other hand, a remarkable morphological change and a substantial significant size reduction was evident for the ZnO nanoparticles extracted from inside the cells compared to both, pristine nanoparticles or controls nanoparticles incubated in culture medium. Actually, nearly $70 \%$ of the analysed digested nanocrystals had maximum length below $100 \mathrm{~nm}$ (Fig. 3B). To assess whether the observed difference on the maximal crystal length among the 3 populations (pristine, control and intracellular nanoparticles) was significant from a statistical point of view, we applied different statistical contrast methods. The nearly zero $p$-value obtained from the Kruskal-Wallis ANOVA test $(p$-value $=2.2 .10-16, \alpha=0.05)$ corroborated that the maximal ZnO crystal length was significantly different at the 0.05 level among the three nanoparticle populations here studied.

As an additional experimental approach, we also employed Raman spectroscopy as a proof of concept to validate the progressive disappearance of the intracellular spectroscopic signature of $\mathrm{ZnO}$ in life cells during $5 \mathrm{~h}$. As shown in Fig. 3C (see also Fig. S4B) we observed the presence of the two characteristic vibrational modes of $\mathrm{ZnO}, \mathrm{E}_{2 \mathrm{High}}$ and $\mathrm{E}_{2 \mathrm{Low}}$, at 439 and $99 \mathrm{~cm}-1$, respectively, in cells exposed to $\mathrm{ZnO}$. The broad feature between 300 and $500 \mathrm{~cm}^{-1}$ is due to the amorphous CaF $\mathrm{F}_{2}$ substrate. Interestingly, the intensity of the Raman peaks clearly decreased during exposure time suggesting the progressive intracellular disappearance of the detectable nano-ZnO. In addition, a fit of the Raman spectra by Lorentzian functions shows a broadening of ZnO peaks (Figs. $3 \mathrm{C}$ and $\mathrm{S} 4 \mathrm{C}, \mathrm{E}_{2 \mathrm{High}}$ mode). This result would indicate an increase of disorder in the $\mathrm{ZnO}$ nanoparticles during the progressive disappearance process. In the particular case of $\mathrm{ZnO}$, the frequency of the Raman modes of $\mathrm{E}_{2 \mathrm{High}}$ and $\mathrm{E}_{2 \mathrm{Low}}$ symmetry are less 
sensitive to disorder. As a whole all these findings demonstrate that ZnO-nanoparticles significantly dissolve inside human keratinocytes in a period of approximately $5 \mathrm{~h}$.

\section{Intracellular $\mathrm{ZnO}$ dissolution triggers actin filament bundling and tubulin macrotube assembly.}

The observed collapse in HaCat and HeLa cells is highly indicative of a cytoskeleton failure. Actin microfilament and microtubule defects were investigated on ZnO-treated immunostained cells using high-resolution confocal microscopy and electron microscopy (see the experimental section). As shown in Fig. 4, cells exposed to large dosages of ZnO nanoparticles displayed a fast and massive reorganization of the cellular cytoskeleton. Actin microfilaments reorganization into cell bundles was observable $2 \mathrm{~h}$ after nanoparticle exposure (Figs. 4A, S5, red channel) while longer exposure times produced a spiky actin organization (Fig. 4B, red arrows) in some cells, while in others polymerized actin was no longer detectable.

Microtubules also suffered a massive reorganization in all cells exposed to nano-ZnO. Tubulin changes were clearly detectable 1-2 $\mathrm{h}$ after nanoparticle exposure. The microtubule intracellular network that typically irradiates from the centrosome in control cells became unfocussed and disorganized. Most tubulin polymers were straight and formed bundles that surrounded and wrapped the nucleus. These findings suggested an enhancement of microtubule stability. Longer exposure times completely reorganised the microtubule network, produced the shortening of these protein nanotubes and the disappearance of microtubules from the periphery of the cell. Tubulin finally assembled straight thick polymers running through the cytoplasm of the cell, literally stabbing the cell membrane (Fig. 4B, green arrows). This microtubule network changes, never before described in cultured cells, suggested an extreme microtubule structural transformation.

To further test this hypothesis, we compared the effect of nano- $\mathrm{ZnO}$ nanoparticles to that of $\mathrm{TiO}_{2}$ and $\mathrm{SiO}_{2}$-coated $\mathrm{ZnO}$ nanoparticles in these cells. Fig. $4 \mathrm{C}$ shows how dosages of $100 \mu \mathrm{g} / \mathrm{mL}$ of $\mathrm{TiO}_{2}$ produced no observable effects, while exposure to $\mathrm{SiO}_{2}$-coated $\mathrm{ZnO}$ nanoparticles significantly prolonged cell survival.

Electron microscopy images of ZnO-treated cells revealed evident signs of necrosis, typically (i) a patent loss of cell membrane integrity, (ii) changes in the chromatin organization, (iii) numerous vacuoles in the cytoplasm filled with cellular remnants, (iv) mitochondrial destruction, etc. (Fig. 5A). Remarkably, bundles of actin, measuring up to $500 \mathrm{~nm}$ wide (Fig. 5A-5B, red arrow), and bundles of macrotubes of tubulin (green arrows) were observed in most ZnO-treated cells devoid of standard microtubules. Macrotube tubulin bundling and cytoplasmic membrane stabbing was also observable in some cells exposed to ZnO for longer times (Fig. 5B, inset 3).These tubulin macrotubes, with diameters from 40 to $65 \mathrm{~nm}$ or even larger, were indistinguishable to the tubulin polymers described by Sites, et al. ${ }^{25}$ assembled in vitro in presence of excess $\mathrm{Zn}$. Ordinary microtubules (24 nm diameter)were only observed in cells that had been exposed to low $\mathrm{ZnO}$ concentrations and for shorter periods of time (Fig. 5C, D). These images together with the immuno-detection of tubulin in these polymers (Fig. 4B, green arrows) confirmed that microtubules in ZnO-treated cells were undergoing a dramatic structural change assembling aberrant tubulin macrotubes due to the massive amounts of intracellular $\mathrm{Zn}^{2+}$.

\section{ZnO nanoparticles can trigger genome instability}

Microtubules and actin filaments are critical components of the cell division machinery. Both polymers are built of protein subunits, tubulin and actin, respectively, that polymerize into $4 \mathrm{~nm}$ wide nanofilaments that organize into cytoplasmic nanotubes -the microtubules-, or a twisted double filament known as the actin microfilament. These cytoskeletal proteins are ubiquitous in all eukaryotic cells representing a large proportion of the total soluble cytoplasmic protein pool. Microtubules and actin filaments are continuously undergoing polymerization-depolymerization processes that are exquisitely controlled by a plethora of intracellular proteins. In microtubules, the polymer dynamics increases up to 100 times during cell division in order to assemble a functional mitotic spindle responsible for the precise separation of the genetic loads of the two daughter cells (Fig. 6A). ${ }^{28}$ Any interference with microtubule dynamics during cell division produces aberrant spindles leading to apoptosis, or to unbalanced chromosome distribution in the daughter cells.

To investigate the effect of nano-ZnO in cell division we examined the morphology of the mitotic spindles in ZnO-treated cells. As shown in Fig. 6B, we found many different versions of aberrant spindles in these cells. These microtubule structures were often disorganized, unfocussed or irregular (green arrows). Actin distribution in ZnO-exposed cells also presented unusual patterns forming actin trails around the cells, intracellular or cortical aberrant actin deposits, etc. (red arrows). Chromosomes in most of these cells appeared compacted and irregularly distributed throughout the cytoplasm. These findings corroborate microtubule and actin filament incompetence in $\mathrm{ZnO}$ treated cells and suggest that these nanomaterials can trigger severe mitotic aberrations leading to genome instability and chromosome malsegregation (known as aneuploidy), both preceding cell transformation and cancer. ${ }^{55}$ 


\section{Discussion}

Zinc intracellular dyshomeostasis can trigger many cell death cascades considering the number of cellular processes and signalling pathways Zinc is involved in. Both, apoptosis ${ }^{14,19,43,48-50}$ and necrosis ${ }^{51}$ have been previously reported in response to ZnO treatment. Most studies coincide that intracellular ZnO provokes elevated ROS stress, mitochondrial superoxide formation, depolarization of mitochondrial membrane, finally leading to apoptosis several days after nano-ZnO treatment. ${ }^{14,19,43,48-50}$ Under our experimental conditions, ROS production occurred later than the observed generalized cell collapse (Fig. S6) thus, a direct implication in necrosis can be ruled out.

Here we report for the first time how both, actin microfilaments and microtubules undergo dramatic structural modifications as a result of $\mathrm{ZnO}$ intracellular dissolution, triggering a fast necrotic process in most cells. This effect is dose-dependent, and is detectable minutes after $\mathrm{ZnO}$ exposure. Our work shows how microtubules polymerize into aberrant straight tubulin macrotubes that form intracellular bundles. These sharp straight polymers appear to perforate the cell membrane and might be the primary cause of the observed early necrotic process. Actin microfilament bundling is also obvious in most cells.

In this scenario, there is also room for a biochemical explanation of the widely reported ROS-triggered apoptotic cell death process. Both, microtubule $s^{56}$ and actin filaments ${ }^{28}$ are continuously undergoing polymerization-depolymerization processes in the cell, and these dynamics represent a huge intracellular energy drain. The calculated average energy that microtubules and actin filaments require in non-dividing cells can represent up to one third of the total energy in cellular events such as cell division. Thus, microtubules and actin consume as much energy as the membrane ATPases in the average cell. ${ }^{57}$ Moreover, recent studies show how actin filament stabilization, by either molecular or chemical means, triggers apoptosis by itself, ${ }^{58}$ and also how the actin cytoskeleton is a physiological regulator of ROS release from mitochondria and a key element in the upstream activation of cell death pathways. ${ }^{59}$ We believe chemical stabilization of microtubules and actin by Zinc could produce among others, a retrograde ATP saturation in the whole cell that could trigger a deleterious feedback effect in mitochondria, producing ROS accumulation, finally leading to apoptotic cell death.

\section{Conclusions}

Our results demonstrate how conventional ZnO nanoparticles used in cosmetics are engulfed by keratinocytes and epithelial cells, these nanoparticles partially dissolve intracellularly triggering a massive cytotoxic dose-dependent effect resulting in a severe cytoskeletal incompetence (Fig. 7). Only future studies in live animals will provide new clues about the dosages, administration routes and modifications required on $\mathrm{ZnO}$ nanoparticles currently used in everyday products to turn these nanomaterials more biocompatible. There is now enough evidence in the literature to be aware of the possible health risks these nanoparticles could represent in damaged skin, or mucosas -such as eyes or mouth in small children- where exposure to nano-ZnO could inevitably lead significant cell damage, cytotoxic effects or even aneuploidies that could eventually lead to cell transformation and cancer.

\section{Acknowledgements}

We thank Dr M. López-Pérez for his helpful discussions, Dr. I. Casafont for his help with the electron-microscopy cell processing and Drs. Jorcano and Quintanilla for providing the HaCat cell line. Ms. M. Aramburu for her technical help. This work has been supported by the Spanish ISCIII-MINECO under Projects ref. PI13/01074, AES 2013; FONDOS FEDER; MAT2012-38664-C02-01. We especially thank the IDIVAL for their support to LGH and the IDIVAL-Microscopy Unit for all the microscopy imaging. 


\section{References}

1 E. K. Dufour, T. Kumaravel, G. J. Nohynek, D. Kirkland and H. Toutain, Mutat. Res. - Genet. Toxicol. Environ. Mutagen., 2006, 607, 215224.

2 E. Demir, H. Akça, B. Kaya, D. Burgucu, O. Tokgün, F. Turna, S. Aksakal, G. Vales, A. Creus and R. Marcos, J. Hazard. Mater., 2014, 264, 420-429.

3 J. Y. Kwon, S. Y. Lee, P. Koedrith, J. Y. K. Lee, K. M. Kim, J. M. Oh, S. I. Yang, M. K. Kim, J. Y. K. Lee, J. Jeong, E. H. Maeng, B. J. Lee and Y. R. Seo, Mutat. Res. - Genet. Toxicol. Environ. Mutagen., 2014, 761, 1-9.

4 J. Zhou, N. Xu and Z. L. Wang, Adv. Mater., 2006, 18, 2432-2435.

5 S.-W. Bian, I. A. Mudunkotuwa, T. Rupasinghe and V. H. Grassian, Langmuir, 2011, 27, 6059-6068.

6 I. A. Mudunkotuwa, T. Rupasinghe, C.-M. Wu and V. H. Grassian, Langmuir, 2012, 28, 396-403.

7 N. A. Monteiro-Riviere, K. Wiench, R. Landsiedel, S. Schulte, A. O. Inman and J. E. Riviere, Toxicol. Sci., 2011, 123, $264-280$.

8 M. J. Osmond-McLeod, Y. Oytam, J. K. Kirby, L. Gomez-Fernandez, B. Baxter and M. J. McCall, Nanotoxicology, 2013, 5390, 1-13.

9 A. V Zvyagin, X. Zhao, A. Gierden, W. Sanchez, J. A. Ross and M. S. Roberts, J. Biomed. Opt., 2011, 13, 064031.

10 B. Gulson, M. McCall, M. Korsch, L. Gomez, P. Casey, Y. Oytam, A. Taylor, M. Mcculloch, J. Trotter, L. Kinsley and G. Greenoak, Toxicol. Sci., 2010, 118, 140-149.

11 B. Gulson, H. Wong, M. Korsch, L. Gomez, P. Casey, M. McCall, M. McCulloch, J. Trotter, J. Stauber and G. Greenoak, Sci. Total Environ., 2012, 420, 313-318.

12 T. Xia, M. Kovochich, M. Liong, L. Mädler, B. Gilbert, H. Shi, J. I. Yeh, J. I. Zink and A. E. Nel, ACS Nano, 2008, 2, $2121-2134$.

13 S. A. James, B. N. Feltis, M. D. De Jonge, M. Sridhar, J. A. Kimpton, M. Altissimo, S. Mayo, C. Zheng, A. Hastings, D. L. Howard, D. J. Paterson, P. F. A Wright, G. F. Moorhead, T. W. Turney and J. Fu, ACS Nano, 2013, 7, 10621-10635.

14 A. Sasidharan, P. Chandran, D. Menon, S. Raman, S. Nair and M. Koyakutty, Nanoscale, 2011, 3, 3657-3669.

15 L. M. Martorano, C. J. Stork and Y. V. Li, J. Cosmet. Dermatol., 2010, 9, 276-286.

16 B. Wang, W. Feng, M. Wang, T. Wang, Y. Gu, M. Zhu, H. Ouyang, J. Shi, F. Zhang, Y. Zhao, Z. Chai, H. Wang and J. Wang, J. Nanoparticle Res., 2008, 10, 263-276.

17 D. Wang, D. Guo, H. Bi, Q. Wu, Q. Tian and Y. Du, Toxicol. In Vitro, 2013, 27, 2117-2126.

18 K. H. Müller, J. Kulkarni, M. Motskin, A. Goode, P. Winship, J. N. Skepper, M. P. Ryan and A. E. Porter, ACS Nano, 2010, 4, $6767-6779$.

19 C. Shen, S. A. James, M. D. De Jonge, T. W. Turney, P. F. A Wright and B. N. Feltis, Toxicol. Sci., 2013, 136, 120-130.

20 J. Nriagu, School of Public Health, 2007, 1-8.

21 R. J. Cousins, J. P. Liuzzi and L. A. Lichten, J. Biol. Chem., 2006, 281, 24085-24089.

22 S. Choi and A. J. Bird, Metallomics, 2014, 6, 1198-1215.

23 J. Nriagu, School of Public Health, 2007, 1-7.

24 C. Andreini, L. Banci, I. Bertini and A. Rosato, J. Proteome Res., 2006, 5, 196-201.

25 J. B. C. A. Sites, F. Gaskin and Y. Kress, J. Biol. Chem., 1977, 252, 6918-6924.

26 N. J. Pace and E. Weerapana, ACS Chem. Biol., 2014, 9, 258-265.

27 H. Strzelecka-Gołaszewska, E. Pròchniewicz and W. Drabikowski, Eur. J. Biochem., 1978, 88, 229-237.

28 M. A. Jordan and L. Wilson, Curr. Opin. Cell Biol., 1998, 10, 123-130.

29 Methods In Cell Biology, Volume 24: The Cytoskeleton, Part A: Cytoskeleton Proteins, Isolation and Characterization, Academic Press, 1982.

30 G. R. Eagle, R. R. Zombola and R. H. Himes, Biochemistry, 1983, 22, 221-228.

31 T. J. A Craddock, J. A. Tuszynski, D. Chopra, N. Casey, L. E. Goldstein, S. R. Hameroff and R. E. Tanzi, PLoS One, 2012, 7, (3), e33552

32 R. Melki and M. F. Carlier, Biochemistry, 1993, 32, 3405-3413.

33 H. Larsson, M. Wallin and A. Edström, Exp. Cell Res., 1976, 100, 104-110.

34 E. Nogales, M. Whittaker, R. a. Milligan and K. H. Downing, Cell, 1999, 96, 79-88.

35 J. Löwe, H. Li, K. H. Downing and E. Nogales, J. Mol. Biol., 2001, 313, 1045-57.

36 C. Renero-Lecuna, R. Martín-Rodríguez, J. González, F. Rodríguez, G. Almonacid, A. Segura, V. Muñoz-Sanjosé, D. R. Gamelin and R. Valiente, Chem. Mater., 2015, 26, 1100-1107.

37 W. Stöber, A. Fink and E. Bohn, J. Colloid Interface Sci., 1968, 26, 62-69.

38 D. Balzar, Microstruct. Anal. from Diffr., 1999, 94-126.

39 R. W. Cheary, A. A. Coelho and J. P. Cline, J. Res. Natl. Inst. Stand. Technol., 2004, 109, 1-25

40 R. B. Heller, J. McGannon and A. H. Weber, J. Appl. Phys., 1950, 21, 1283-1284.

41 D. T. Cromer and K. Herrington, J. Am. Chem. Soc., 1955, 77, 4708-4709.

42 C. E. Kril and R. Birringer, Philos. Mag. A, 1998, 77, 621-640.

43 H. C. Bae, H. J. Ryu, S. H. Jeong, E. Y. Lee, Y.-H. Park, K. G. Lee, B. H. Choi, E. H. Maeng, M.-K. Kim and S. W. Son, Mol. Cell. Toxicol., 2011, 7, 333-337.

44 S. H. Lee, H. R. Lee, Y. R. Kim and M. K. Kim, Toxicol. Environ. Health Sci., 2012, 4, 14-18.

45 L. Müller, M. Riediker, P. Wick, M. Mohr, P. Gehr and B. Rothen-Rutishauser, J. R. Soc. Interface, 2010, 7 Suppl 1, S27-S40.

46 P. J. Moos, K. Olszewski, M. M. Honeggar, P. Cassidy, S. Leachman, D. Woessner, N. S. Cutler and J. M. Veranth, Metallomics, 2011, 3, 1- 
28.

47 V. Nikoletopoulou, M. Markaki, K. Palikaras and N. Tavernarakis, Biochim. Biophys. Acta, 2013, 1833, 3448-3459.

48 D. Guo, H. Bi, B. Liu, Q. Wu, D. Wang and Y. Cui, Toxicol. Vitr., 2013, 27, 731-738.

49 R. Roy, S. K. Singh, L. K. S. Chauhan, M. Das, A. Tripathi and P. D. Dwivedi, Toxicol. Lett., 2014, 227, $29-40$.

50 H. J. Yoo and T. H. Yoon, J Nanosci Nanotechnol, 2014, 14, 5395-5401.

51 J.-H. Kim, M. S. Jeong, D.-Y. Kim, S. Her and M.-B. Wie, Neurochem. Int., 2015, 90, 204-214.

52 L. Ouyang, Z. Shi, S. Zhao, F. T. Wang, T. T. Zhou, B. Liu and J. K. Bao, Cell Prolif., 2012, 45, 487-498.

53 G. Plascencia-Villa, C. R. Starr, L. S. Armstrong, A. Ponce and M. José-Yacamán, Integr. Biol., 2012, 4, 1358-1366.

54 B. Gilbert, S. Fakra, T. Xia and S. Pokhrel, ACS Nano, 2012, 4921-4930.

55 M. Giam and G. Rancati, Cell Div., 2015, 10, 3.

56 A. Desai and T. J. Mitchison, Annu. Rev. Cell Dev. Biol., 1997, 13, 83-117.

57 A. Flamholz, R. Phillips and R. Milo, Mol. Biol. Cell, 2014, 25, 3497-3500.

58 C. W. Gourlay and K. R. Ayscough, Nat. Rev. Mol. Cell Biol., 2005, 6, 583-589.

59 C. W. Gourlay, L. N. Carpp, P. Timpson, S. J. Winder and K. R. Ayscough, J. Cell Biol., 2004, 164, 803-809. 


\section{Figures}

A

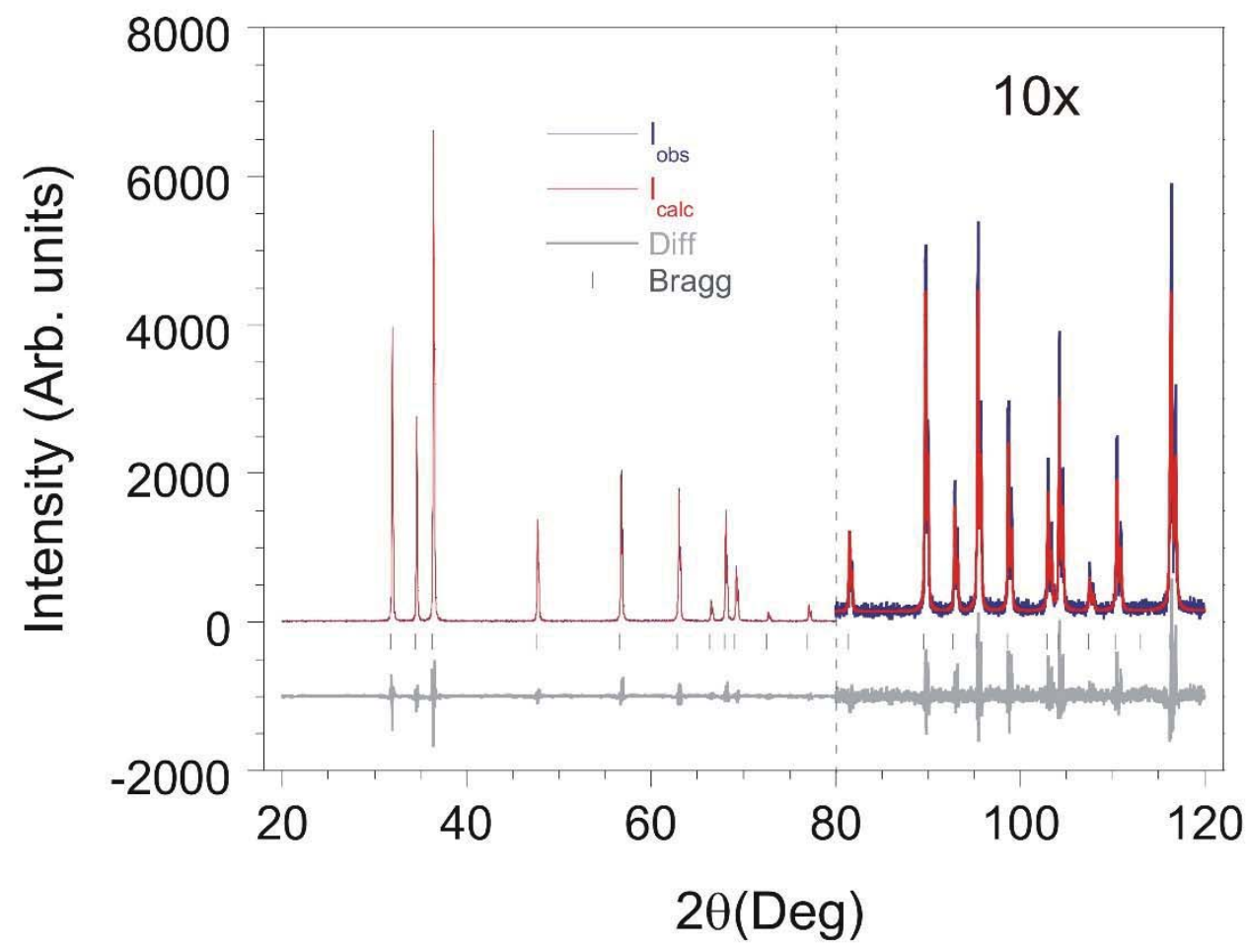

B
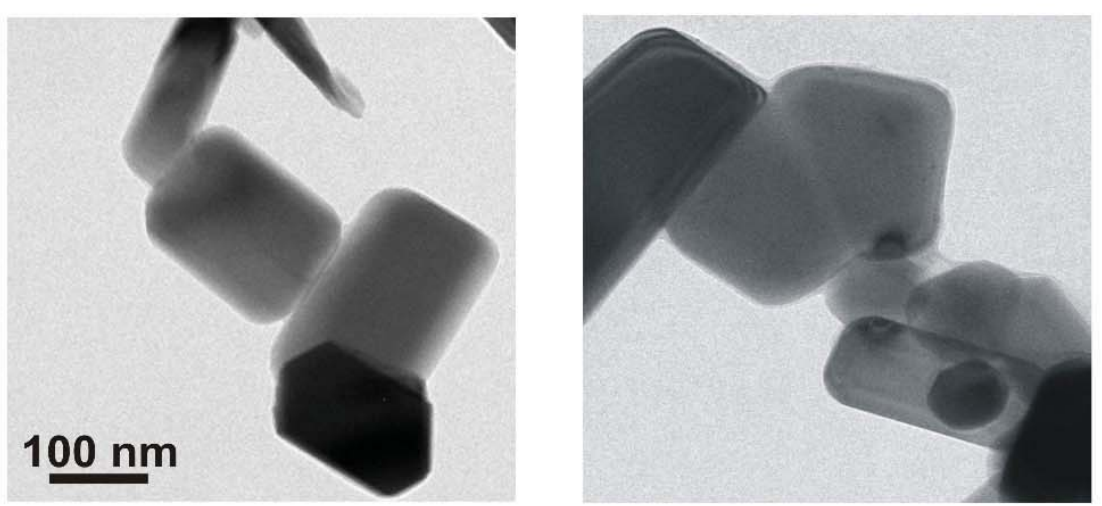

Fig.1 (A) Rietveld refinement of the x-ray diffraction pattern of $\mathrm{ZnO}$ nanoparticles (Z-COTE ${ }^{\circledR}$ ). Data have been rescaled (10x) from the dashed vertical line at 80 to show the less intense reflections above this value. Vertical lines indicate Bragg positions for the space group $P 6_{3} m c$. Among refined parameters are those related to size and effective strain. (B) TEM images of the pristine $\mathrm{ZnO}$ nanoparticles. The morphology of these nanocrystals includes hexagonal prisms, plates and rods of a wide range of sizes. The EDX analysis of the nanoparticles is available as supplementary information (Fig. S4A). 
A

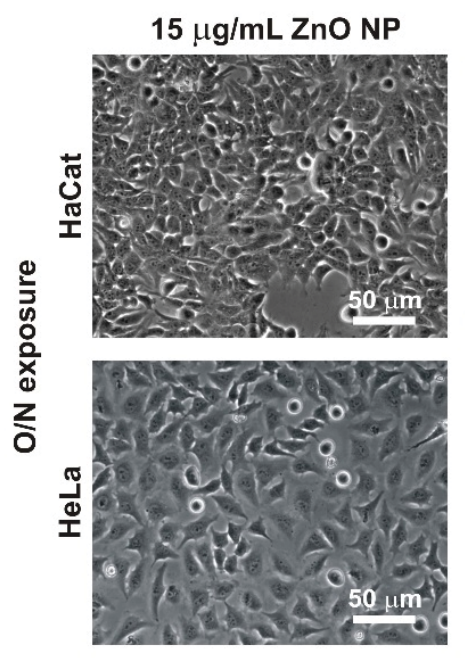

B

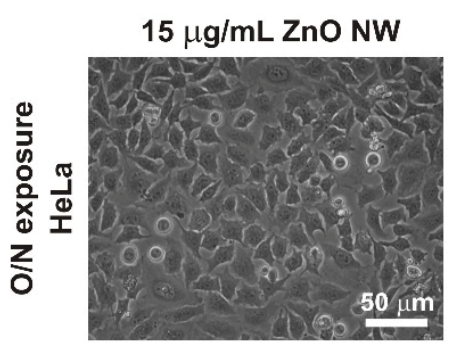

C

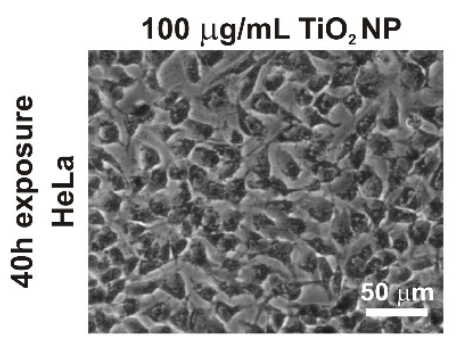

D

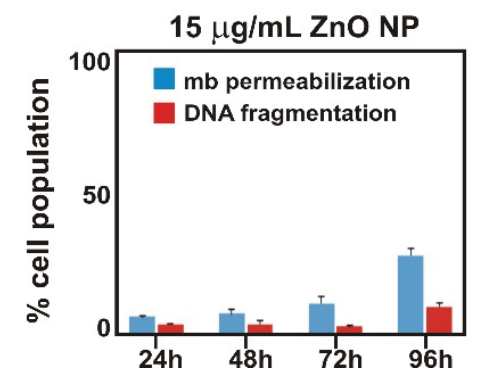

$30 \mu \mathrm{g} / \mathrm{mL} Z \mathrm{ZnO}$ NP
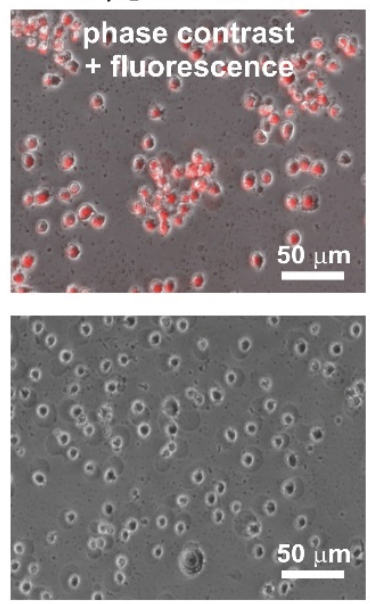

$30 \mu \mathrm{g} / \mathrm{mL}$ ZnO NW
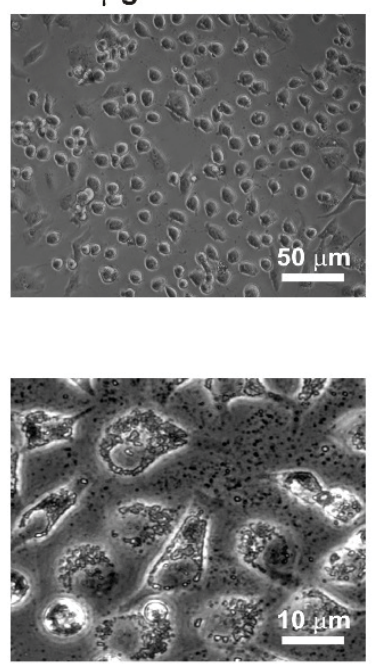

$30 \mu \mathrm{g} / \mathrm{mL}$ ZnO NP

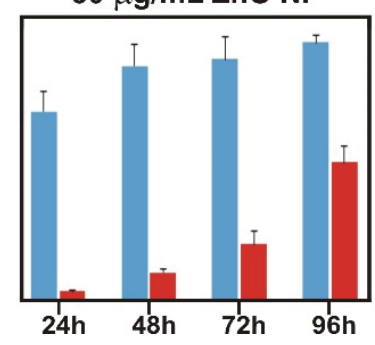

E
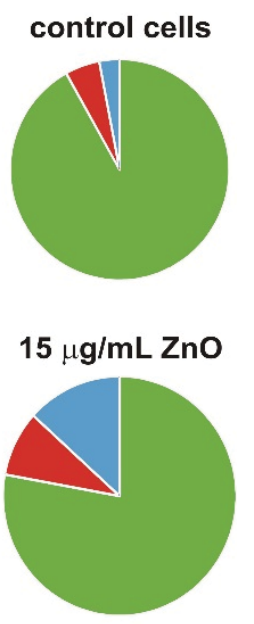

$30 \mu \mathrm{g} / \mathrm{mL} \mathrm{ZnO}$

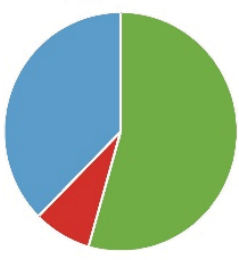

$15 \mu \mathrm{g} / \mathrm{mL} \mathrm{TiO}_{2}$

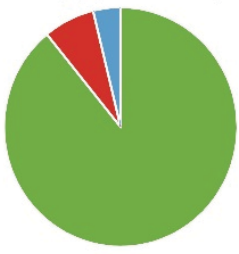

$30 \mu \mathrm{g} / \mathrm{mL} \mathrm{TiO}_{2}$

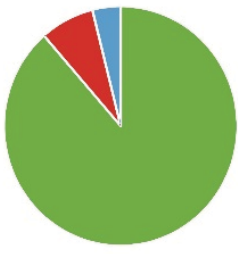

Live cell

Apoptosis

Necrosis

Fig. 2 (A) Phase-contrast image of human keratinocytes (HaCat) and epithelial cells (HeLa) exposed to 15 and $30 \mu g / m L$ of $\mathrm{ZnO}$ nanoparticles overnight $(\mathrm{O} / \mathrm{N})$. Cells exposed to $30 \mathrm{\mu g} / \mathrm{mL}$ of nano-ZnO undergo an acute cell collapse process accompanied by cytoplasmic membrane permeabilisation (top image, red cells) (video S1). (B) HeLa cells exposed to same dosages of ZnO nanowires (NW) displaying an undistinguishable response to that produced by $\mathrm{ZnO}$ nanoparticles. (C) (Left) Exposure to larger dosages (100 $\mu \mathrm{g} / \mathrm{mL}$ ) of anatase $\mathrm{TiO} \mathrm{Z}_{2} \mathrm{nanoparticles}$ do not cause cell collapse $40 \mathrm{~h}$ after exposure. (Right). High magnification phase-contrast image demonstrating cytoplasmic TiO 2 nanoparticles (see also Fig. $\mathrm{S}_{1 \mathrm{~B}}$ ). (D) Time dependent quantification of necrosis (membrane permeabilisation, blue) and apoptosis (DNA fragmentation, red) in nano-ZnO treated cells. DNA fragmentation is patent $96 \mathrm{~h}$ after $30 \mu \mathrm{g} / \mathrm{mL}$ nano-ZnO exposure (see Fig. S2). (E) Pie chart representation of apoptosis (red) and necrosis (blue) $24 \mathrm{~h}$ after ZnO exposure as determined by the Annexin V-vital dye exclusion assay (see Fig. S3). Both studies conclude that dosages of 30 $\mathrm{\mu g} / \mathrm{mL}$ nano-ZnO trigger a massive cell death by necrosis (see Fig. S3), not observable in nano-TiO ${ }_{2}$ treated cells. 

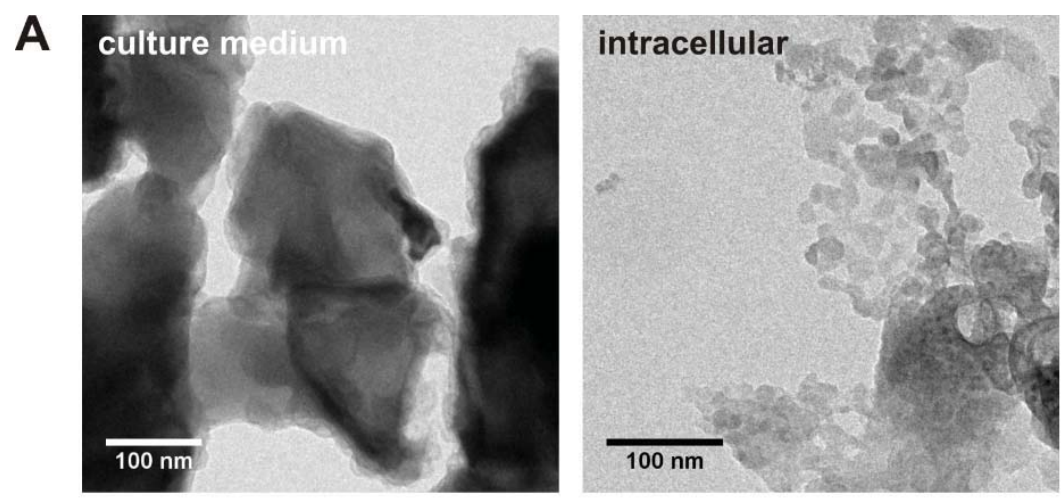

B
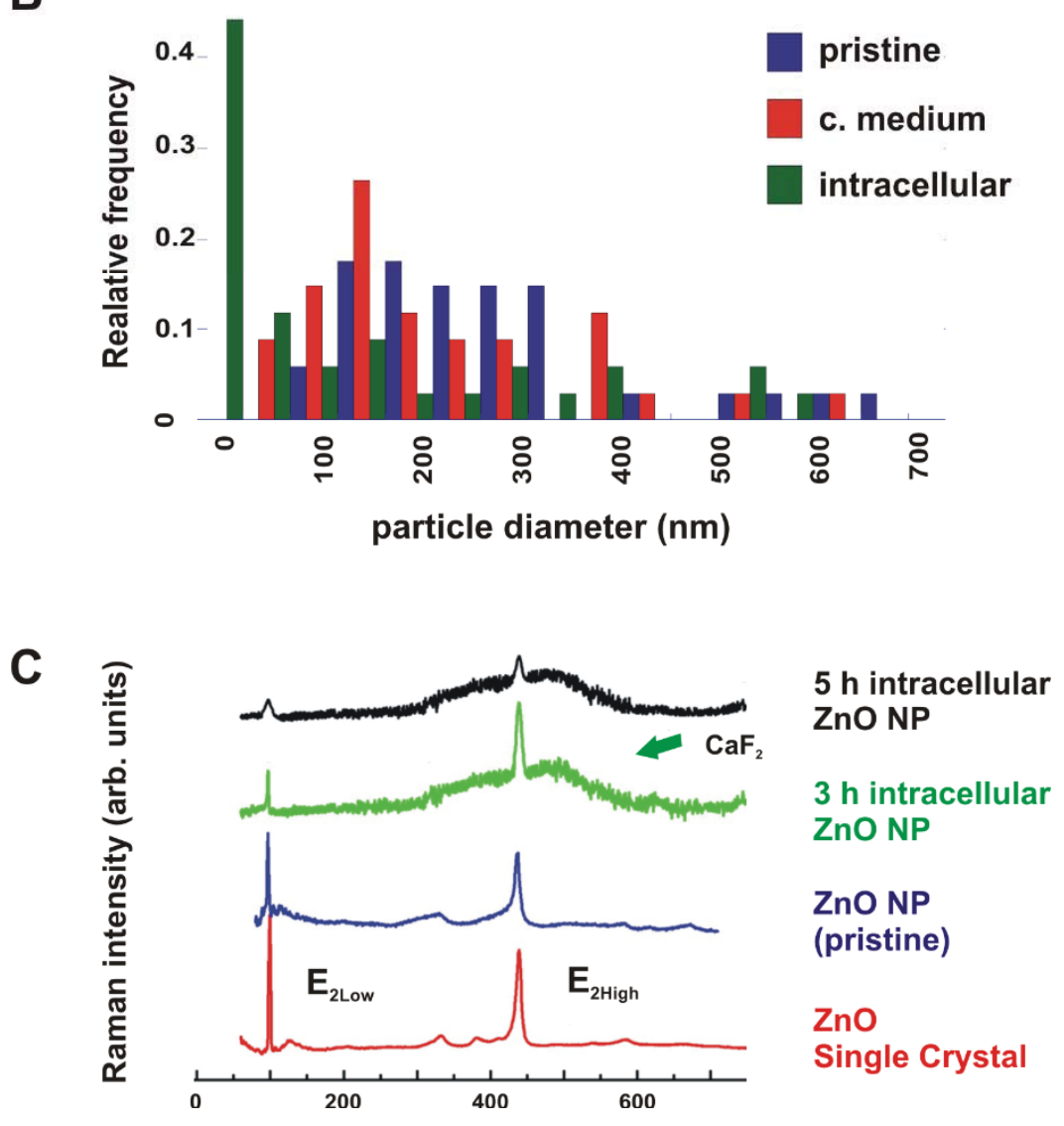

Fig. 3 (A) Representative TEM micrographs of ZnO nanocrystals incubated in cellular media devoid of cells for $5 \mathrm{~h}$ (left), and after being "digested" by human keratinocytes (right). Note the remarkable differences in shape and sizes between the two samples (EDX spectrum available in Fig. S4A). (B) Distribution of the largest axes length of pristine $\mathrm{ZnO}$ nanoparticles (blue), and identical particles after $5 \mathrm{~h}$ after recovery from cell culture media (red) or cells (green). Large particles could correspond to aggregates. (C) Raman spectroscopic signatures of the intracellular ZnO in a single HaCat cell studied in vivo. Intracellular spectra were obtained $3 \mathrm{~h}$ (green) and $5 \mathrm{~h}$ (black) after ZnO nanoparticle engulfment (see Fig. S4B). Raman spectra of the pristine nanoparticles (blue) and $\mathrm{ZnO}$ single crystals (red) are included for comparison. 
A

Nuclear DNA/microtubules/actin
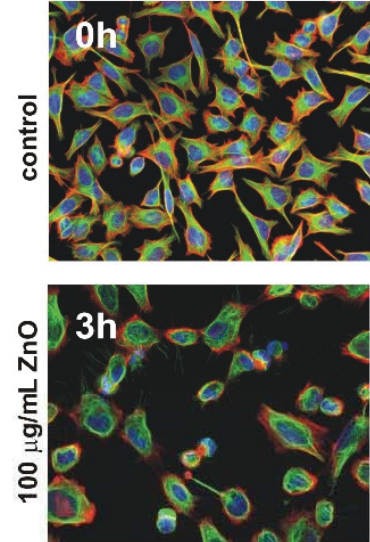

C

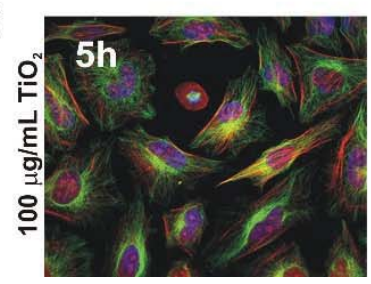

B
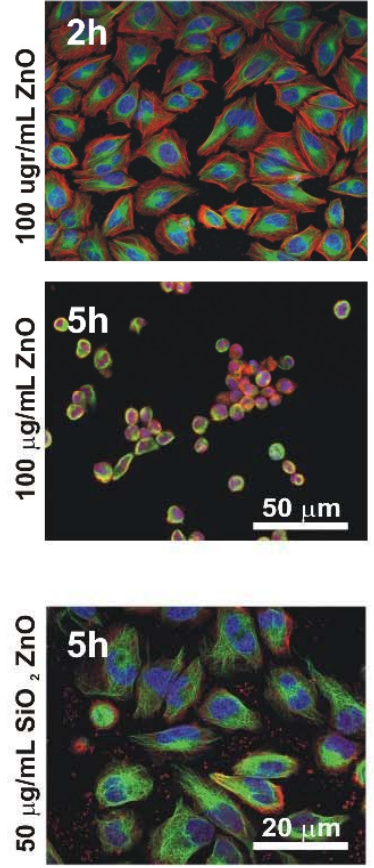

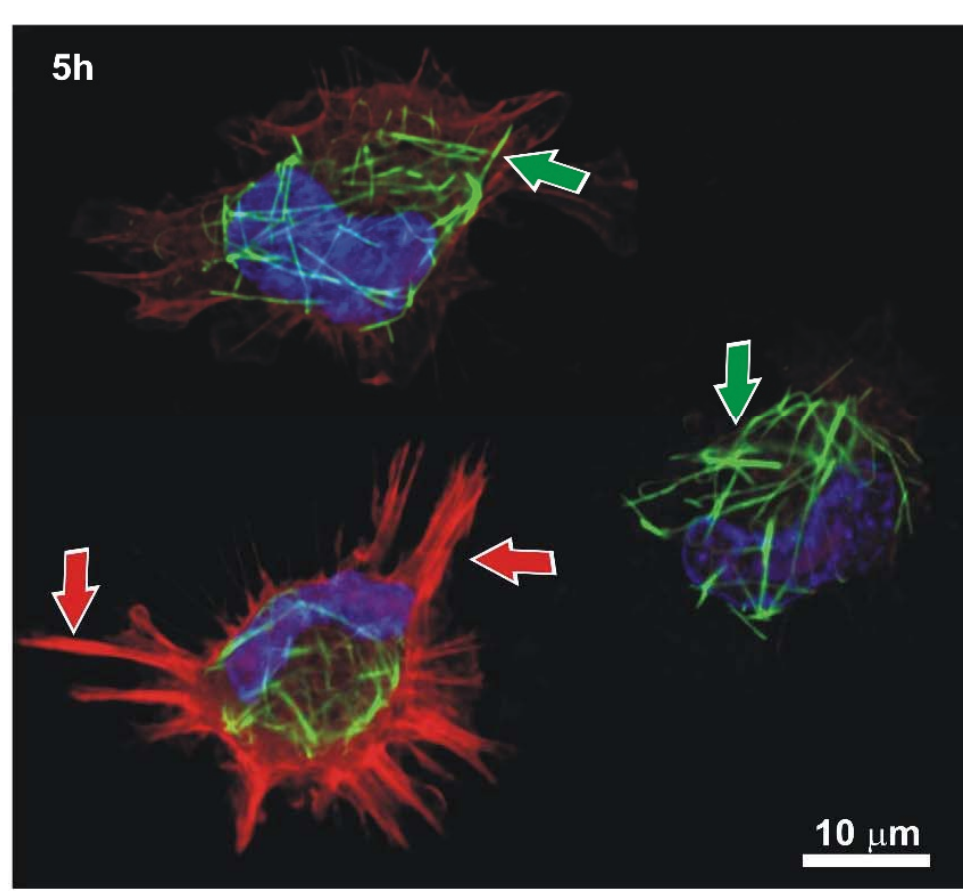

Fig. 4 (A) Confocal microscopy images of cells exposed to nano-ZnO. Cell collapse is very noticeable $5 \mathrm{~h}$ after exposure to ZnO. (B) Aberrations in the organization of the actin microfilaments (red channel) and microtubules (green channel), such as actin spikes (red arrows) and microtubule straightening, thickening and shortening (green arrows), are observed. Nuclear fragmentation indicative of apoptosis is not evident at these time points (blue channel) (see also Fig S5). (C) Anatase $\mathrm{TiO}_{2}$ nanoparticles $(100 \mu \mathrm{g} / \mathrm{mL})$ do not trigger cell collapse. Exposure to $\mathrm{SiO}_{2}$-coated $\mathrm{ZnO}$ nanoparticles significantly enhances cell viability. 
A

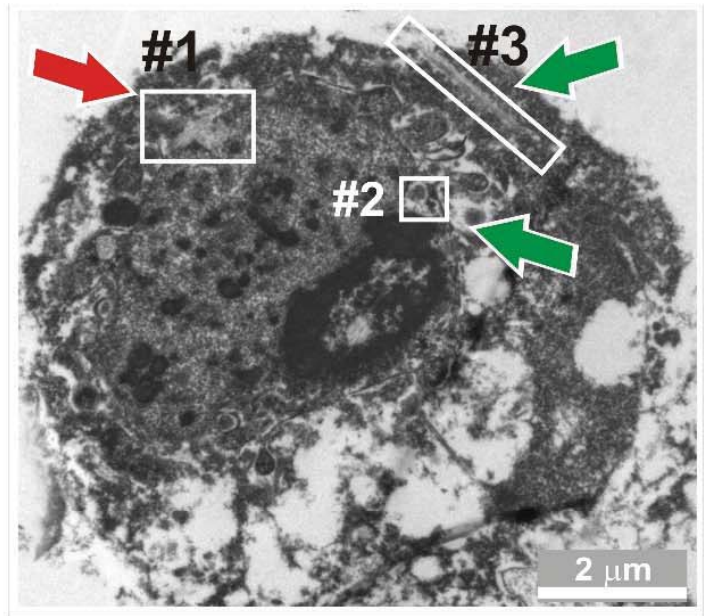

B
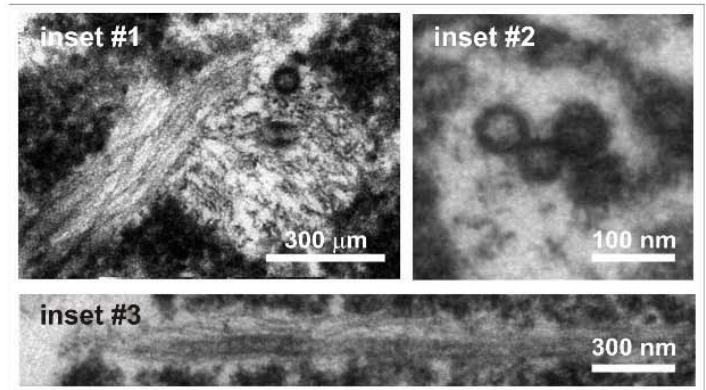

C microtubule/macrotube transversal sections
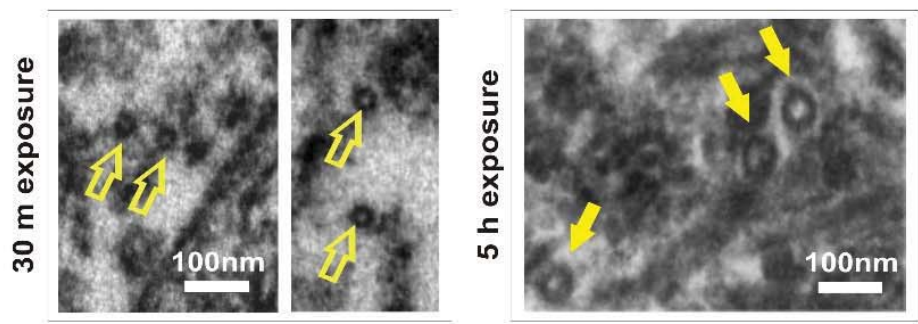

D microtubule/macrotube longitudinal sections

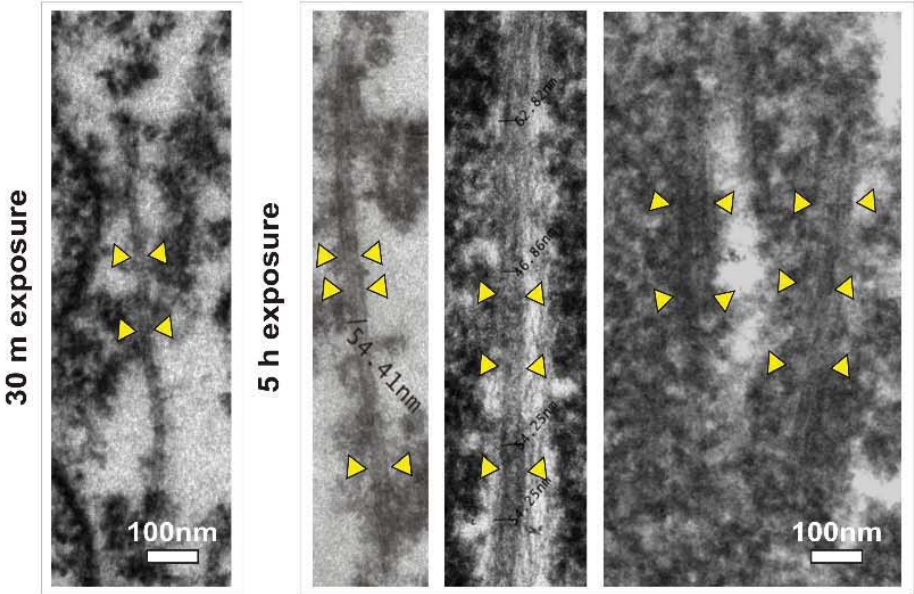

Fig. 5 (A) Transmission electron microscopy images of a necrotic cell exposed to ZnO nanoparticles for $5 \mathrm{~h}$ displaying cytoskeletal abnormalities (insets). (B) Bundles of actin filaments (inset \#1), and large diameter microtubules sectioned transversally (inset \#2) or longitudinally (inset \#3) are observed. These tubulin polymers run parallel to the cell periphery and appear to stab the cell membrane. (C) Transversal and (D) longitudinal microtubule sections obtained 30 min and $5 \mathrm{~h}$ after $\mathrm{ZnO}$ nanoparticle exposure. A patent microtubule diameter enlargement, from the standard size of $24 \mathrm{~nm}$ (empty arrows) to approximately 60 $\mathrm{nm}$ (filled arrows), is observed. 


\section{Chromosomes/actin/spindle microtubules}
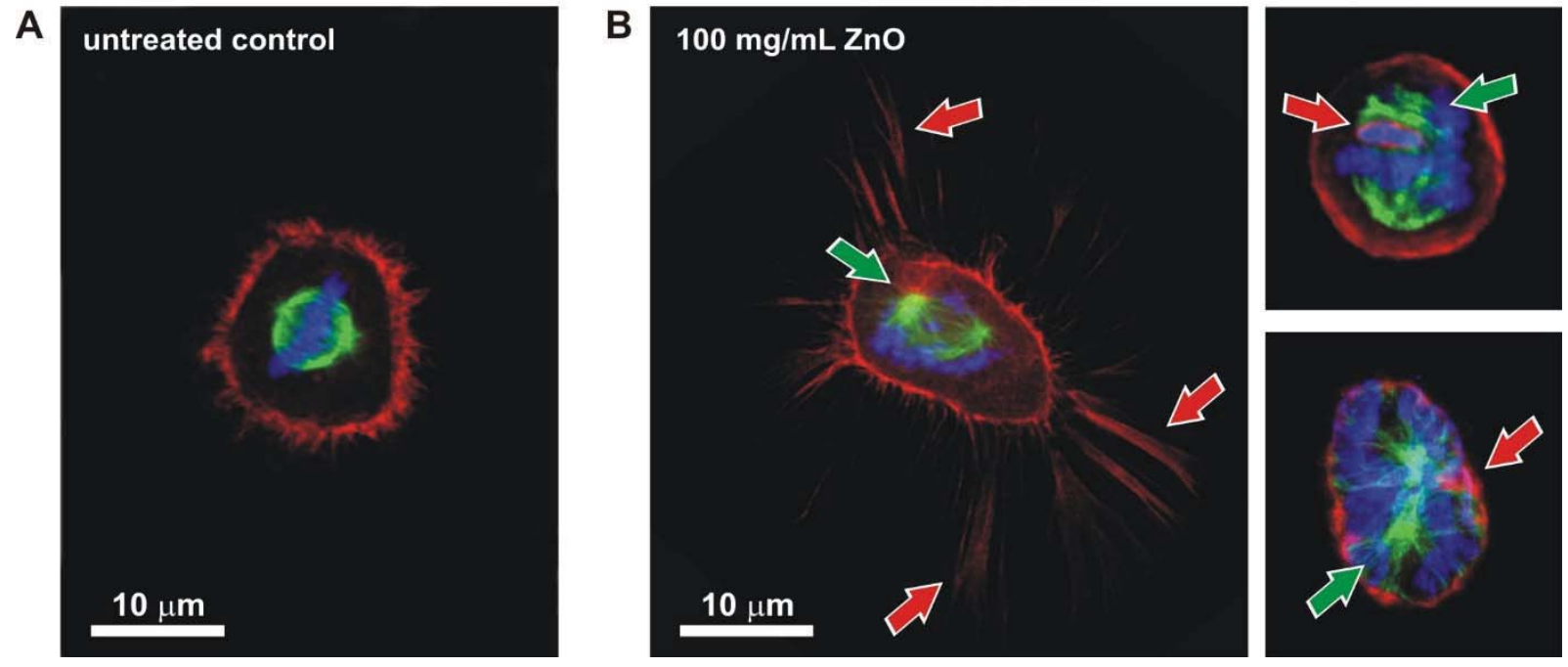

Fig. 6 (A) Single plane confocal microscopy image of a control cell in metaphase. (B) ZnO-treated cells display aberrations in the organization of the spindle microtubules (green channel), actin microfilaments (red channel) and the chromosome distribution (blue channel). Cytoskeletal defects include asymmetric, unfocussed or disorganized microtubule structures (green arrows) accompanied with aberrant actin trails and actin microfilament bundles (red arrows). 


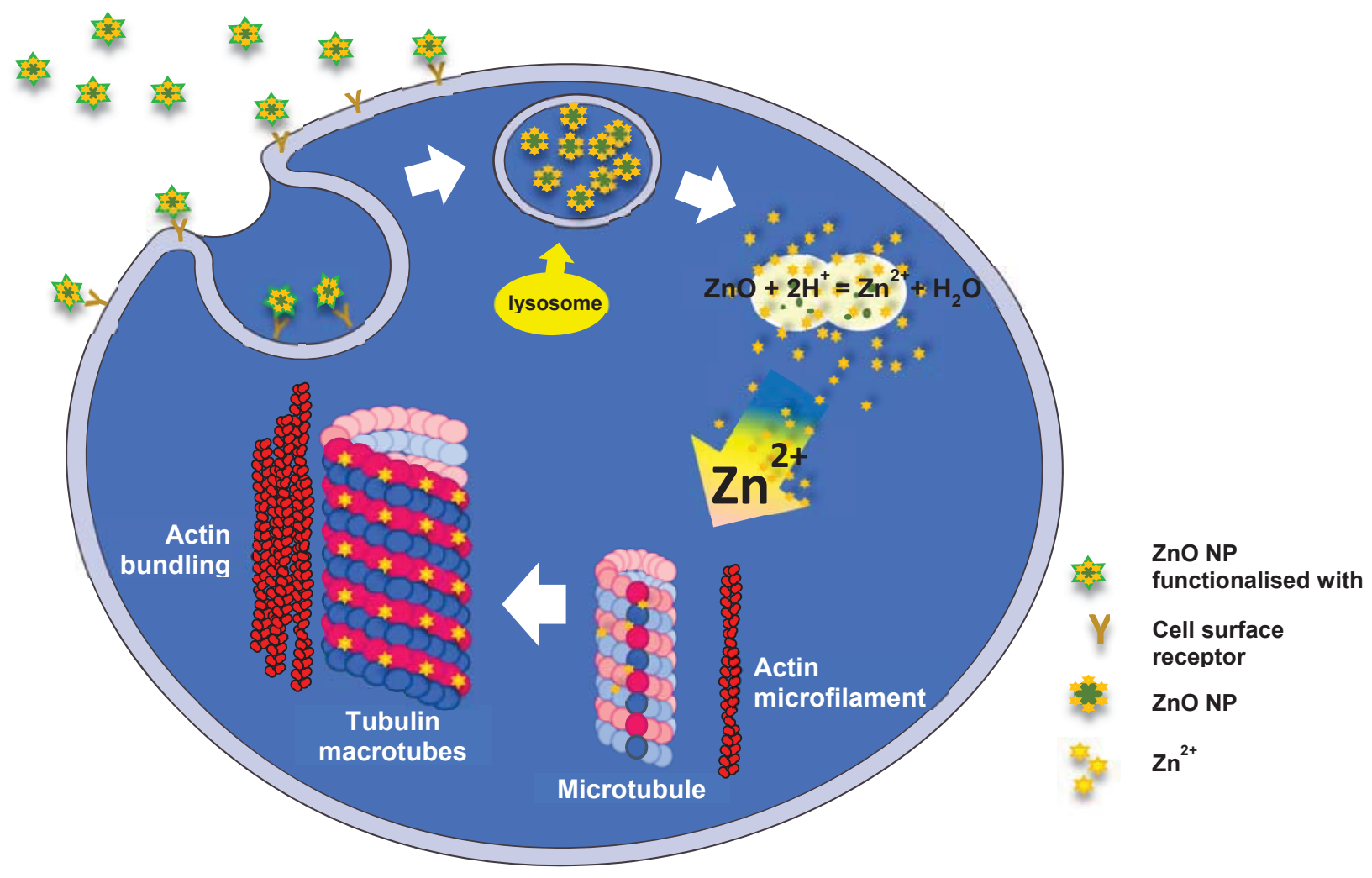

Fig. 7 Diagram of the molecular mechanism of the nano-ZnO cytotoxic effects. Serum protein functionalized ZnO nanoparticles interact with cell surface receptors on the cytoplasmic membrane, being actively endocytosed. Endosomes containing nanoparticles fuse to lysosomes. The low pH of the endolysosomal compartment partially dissolves the ZnO nanoparticles releasing massive amounts in Zinc intracellularly. Tubulin is as Zinc scavenger protein that undergoes structural changes upon Zinc binding, assembling abnormal tubulin macrotubes. 


\section{TOC graphic:}

\section{Nano-ZnO leads to tubulin macrotube assembly and actin bundling triggering cytoskeletal catastrophe and cell necrosis}

Lorena García-Hevia ${ }^{\mathrm{a}}$, Rafael Valiente ${ }^{\mathrm{ab}}$, Rosa Martín-Rodríguez ${ }^{\mathrm{ac}}$, Carlos Renero-Lecuna ${ }^{\mathrm{ab}}$, Jesús González ${ }^{\mathrm{ad}}$, Lidia RodríguezFernández ${ }^{\mathrm{e}}$, Fernando Aguadod, Juan C. Villegas ${ }^{\mathrm{a}}$ and Mónica L. Fanarraga ${ }^{\mathrm{a}}$

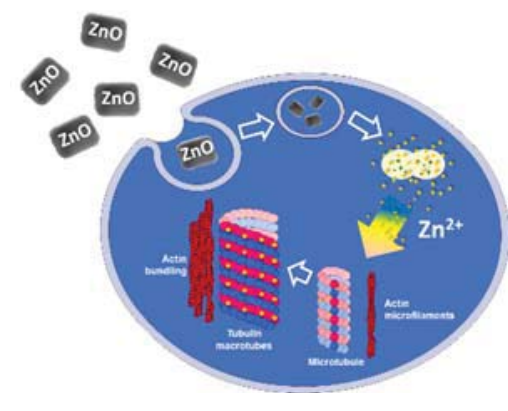

ZnO nanoparticles are engulfed by keratinocytes and dissolve intracellularly, causing cytoskeletal abnormalities, membrane permeabilisation, cellular collapse and death by necrosis. 
Nano-ZnO leads to tubulin macrotube assembly and actin bundling triggering cytoskeletal catastrophe and cell necrosis

Lorena García-Heviaa , Rafael Valiente ${ }^{\mathrm{ab}}$, Rosa Martín-Rodríguez ${ }^{\mathrm{ac}}$, Carlos Renero-Lecuna ${ }^{\mathrm{ab}}$, Jesús González ${ }^{\text {ad }}$, Lidia Rodríguez-Fernández ${ }^{\mathrm{e}}$, Fernando Aguado ${ }^{\mathrm{d}}$, Juan C. Villegas ${ }^{\mathrm{a}}$ and Mónica L. Fanarraga ${ }^{\mathrm{a}}$ 


\section{Supplementary figure 1}

A

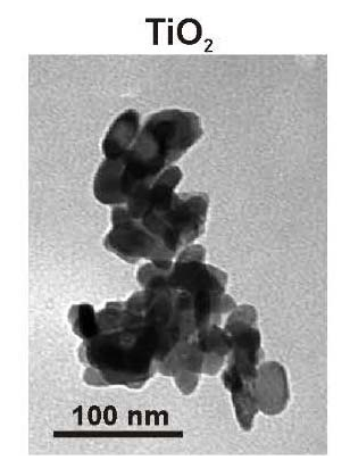

B
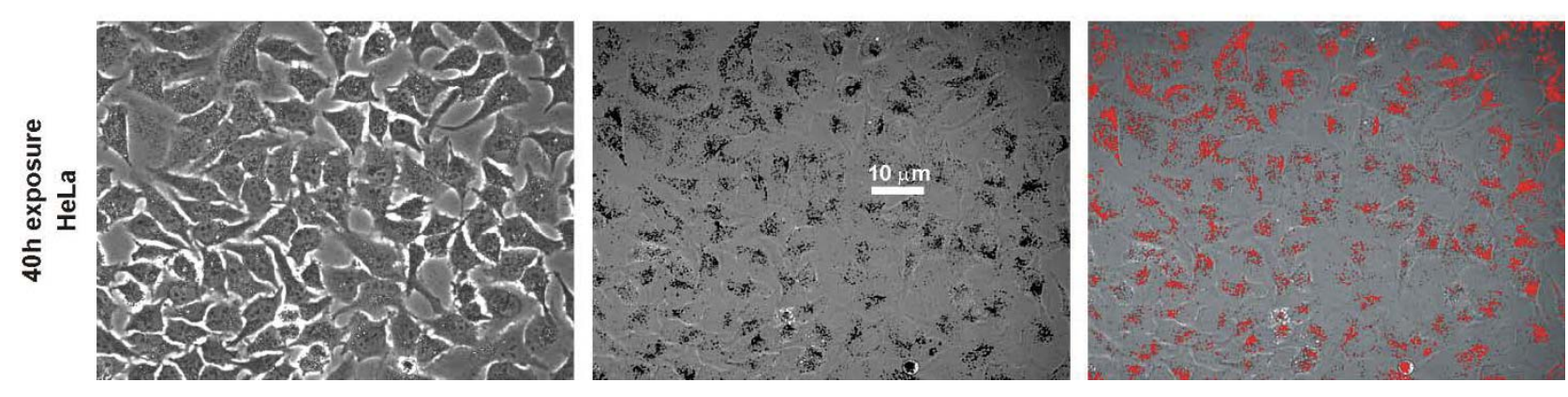

C
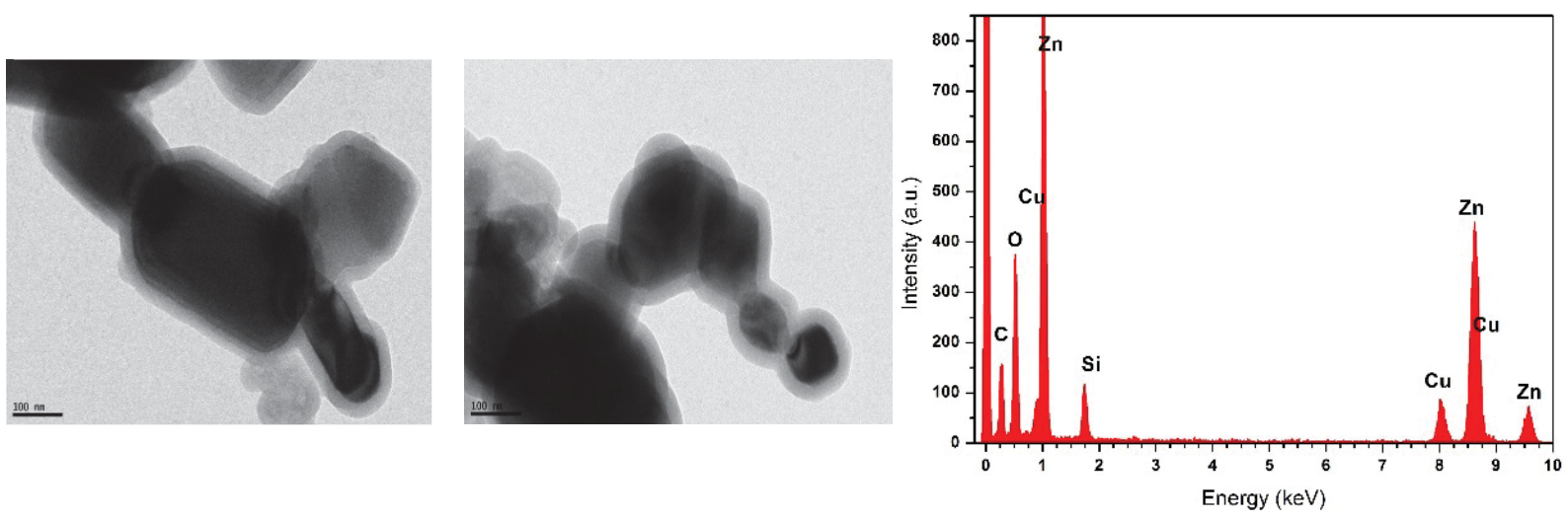

Figure S 1: (A) TEM image of representative $\mathrm{TiO}_{2}$ nanoparticles. (B) Phase-contrast image of human epithelial cells exposed to $100 \mu \mathrm{g} / \mathrm{mL}$ of anatase $\mathrm{TiO}_{2} \mathrm{NP}$ during $40 \mathrm{~h}$. (center). Same image in bright field microscopy showing the intracellular nanoparticles as black intracellular spots. (right) Same image processed with the NIS-Elements Advanced Research software highlighting the $\mathrm{TiO}_{2}$ nanoparticles colored in red for better identification. (C) Transmission electron micrograph of the $\mathrm{SiO}_{2}$-coated $\mathrm{ZnO}$ nanoparticles. (Right) EDX spectrum of the coated ZnO nanoparticles. 


\section{Supplementary Figure 2}

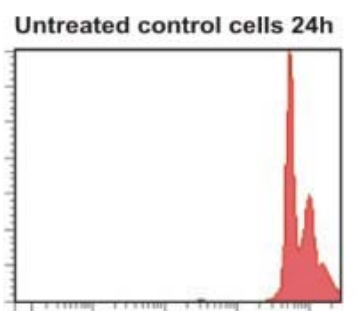

Untreated control cells $48 \mathrm{~h}$

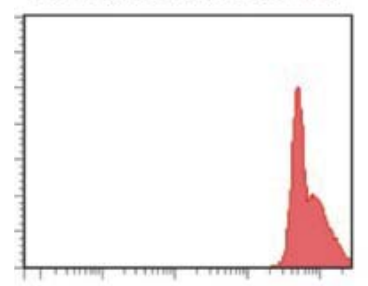

Untreated control cells $\mathbf{7 2 h}$

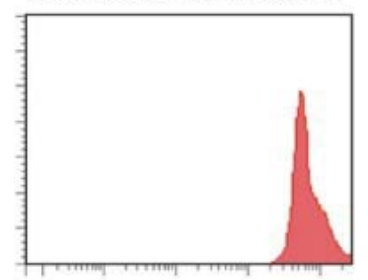

Untreated control cells 96h

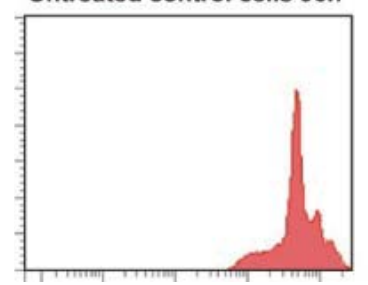

$15 \mu \mathrm{g} / \mathrm{mL}$ ZnO 24h

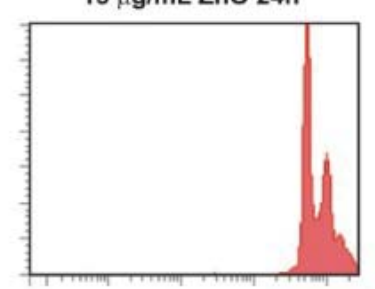

$15 \mu \mathrm{g} / \mathrm{mL} \mathrm{ZnO} 48 \mathrm{~h}$

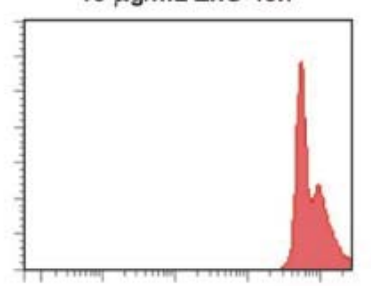

$15 \mu \mathrm{g} / \mathrm{mL} Z \mathrm{nO} 72 \mathrm{~h}$

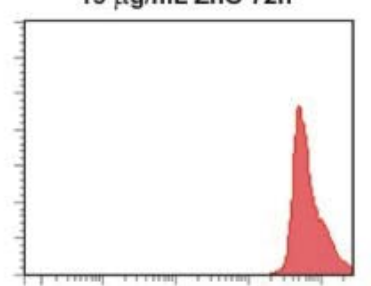

$15 \mu \mathrm{g} / \mathrm{mL}$ ZnO 96h

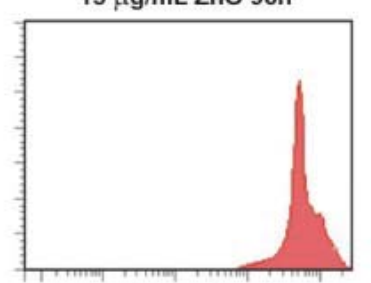

$30 \mu \mathrm{g} / \mathrm{mL}$ ZnO 24h

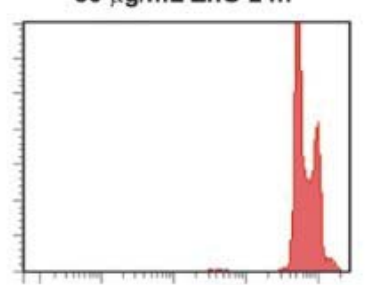

$30 \mu \mathrm{g} / \mathrm{mL} \mathrm{ZnO} 48 \mathrm{~h}$

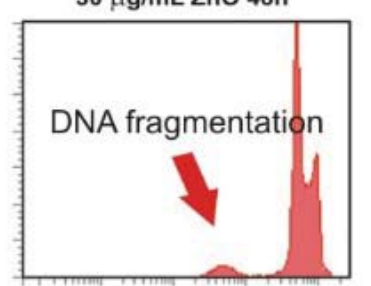

$30 \mu \mathrm{g} / \mathrm{mL} \mathrm{ZnO} 72 \mathrm{~h}$

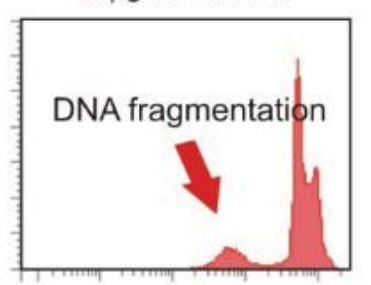

$30 \mu \mathrm{g} / \mathrm{mL} \mathrm{ZnO} 96 \mathrm{~h}$

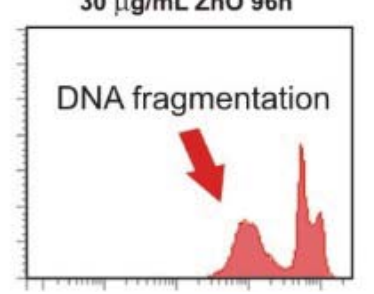

$100 \mu \mathrm{g} / \mathrm{mL}$ ZnO 24h

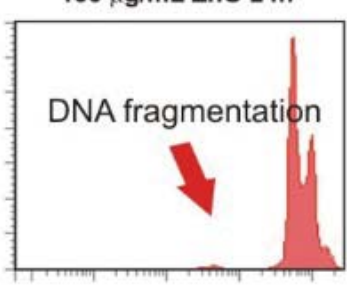

$100 \mu \mathrm{g} / \mathrm{mL} \mathrm{ZnO} 48 \mathrm{~h}$

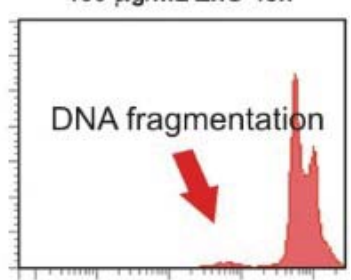

$100 \mu \mathrm{g} / \mathrm{mL}$ ZnO 72h

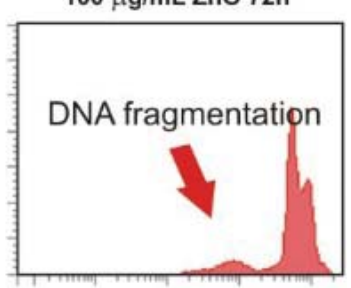

$100 \mu \mathrm{g} / \mathrm{mL} \mathrm{ZnO} 96 \mathrm{~h}$

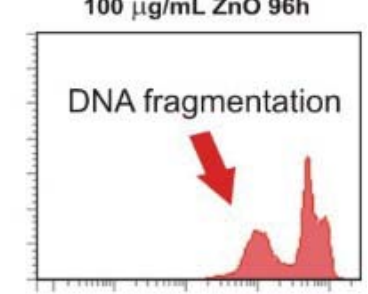

Figure S 2: Original flow cytometry charts used to quantify apoptosis and to elaborate the histograms represented in Figure 2D (red bars). These charts are histograms obtained for approximately 10.000 cells. The amount of DNA per cell is represented in the $X$ axis, and the total number of cells in the $Y$ axis. Arrows indicate the region of the chart where apoptosis is markedly observed. 


\section{Supplementary Figure 3}
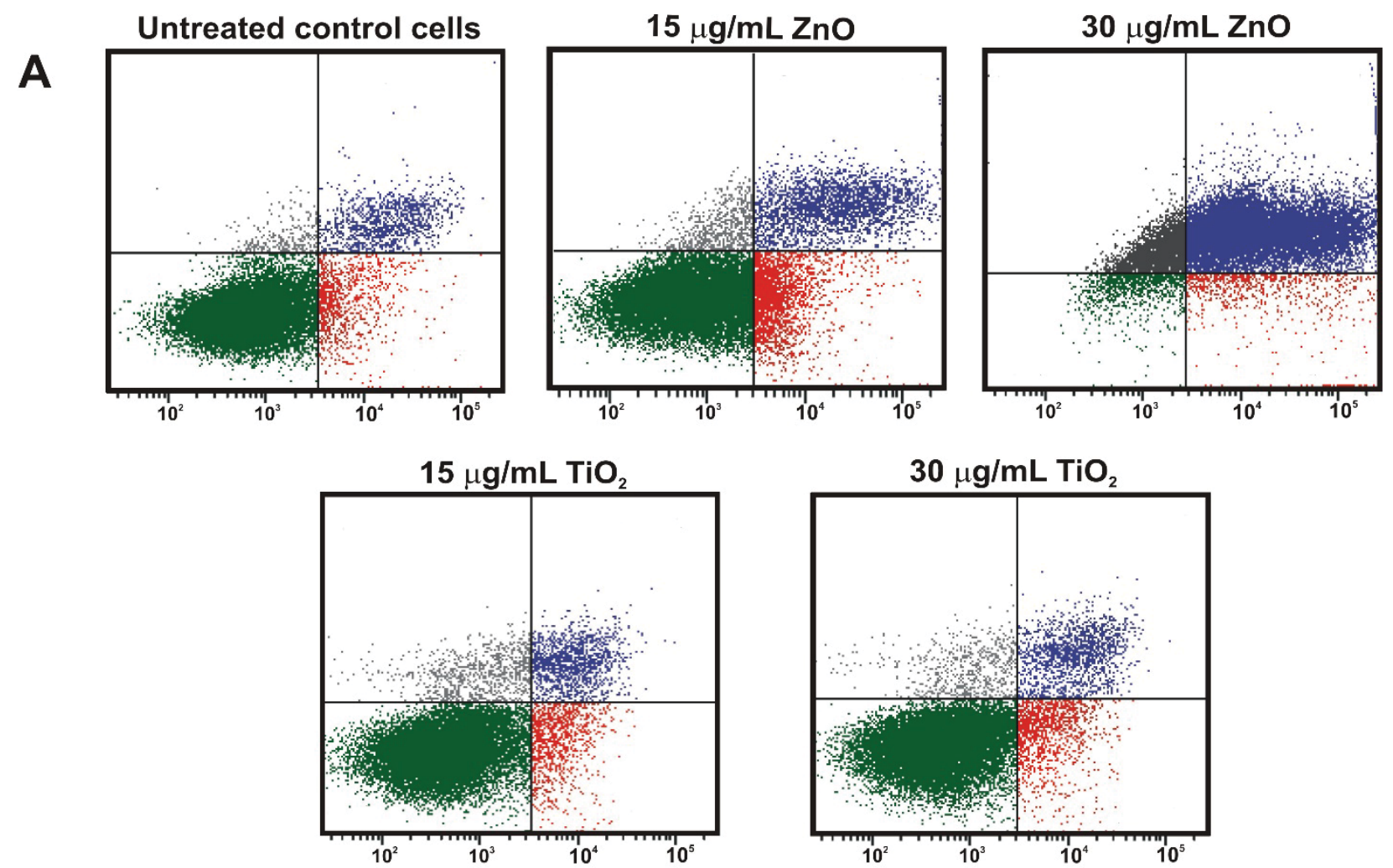

B

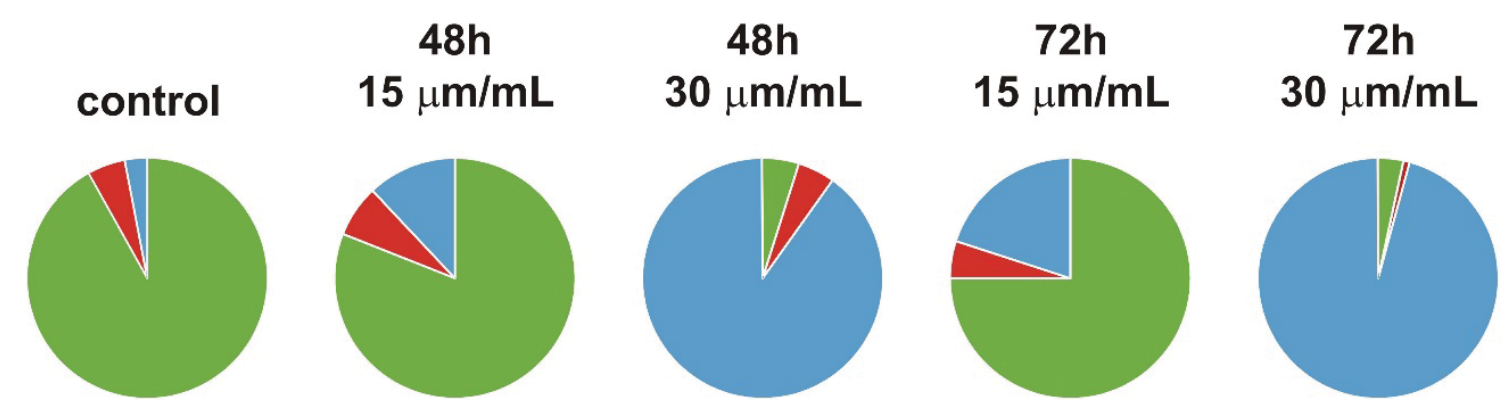

Figure S 3: Flow cytometry charts displaying viable cells (green), apoptotic cells (red), and necrotic cells (blue) obtained for cells exposed to $\mathrm{ZnO}$ for $24 \mathrm{~h}$. These graphs are the original flow cytometry data represented as pie charts in Figure 2E. (B) Time course pie charts representing results obtained for cells exposed to $\mathrm{ZnO}$ during 48 and $72 \mathrm{~h}$. 


\section{Supplementary Figure 4}

A
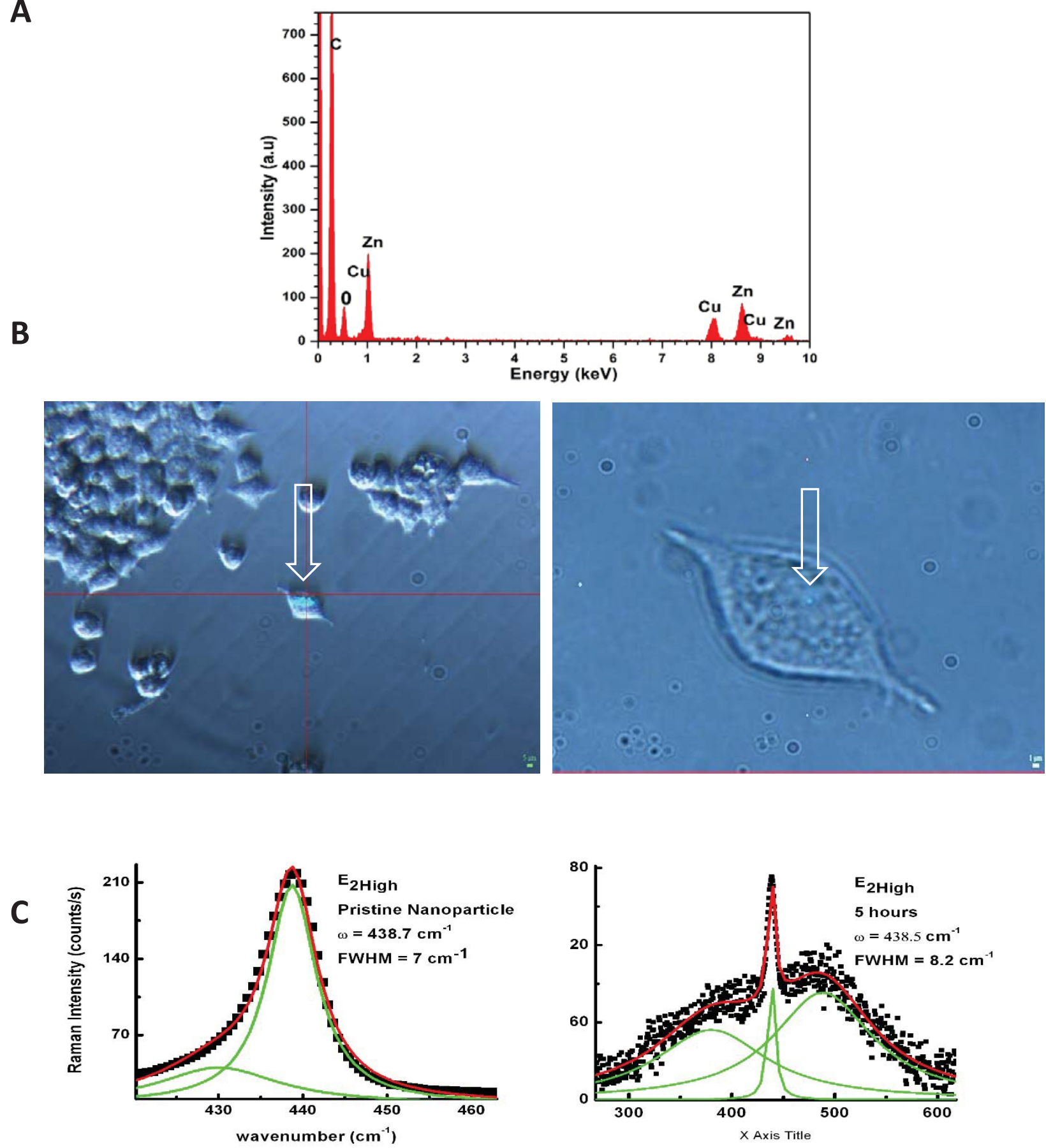

Figure S 4: (A) EDX spectrum of the "digested" ZnO nanoparticles in Figure 4B extracted from inside the keratinocytes. (B) Phase contrast image of HaCat cells captured through 20x (left) and 100x (right) objectives of the confocal Raman microscope during spectroscopic analysis. Arrows point at the laser spots. The sizes of the laser spots can be calculated with the scale bars (right, bottom corner). (C) Lorentzian fit of the Raman spectra of $\mathrm{ZnO}$ nanoparticles in the spectra domain of $\mathrm{E}_{2 \mathrm{High}}$ modes. A slight increase of the full wide at half-maximum (FWHM) Raman mode can be observed while the frequency remains practically constant. 


\section{Supplementary Figure 5}

\section{Nuclear DNA/microtubules/actin}
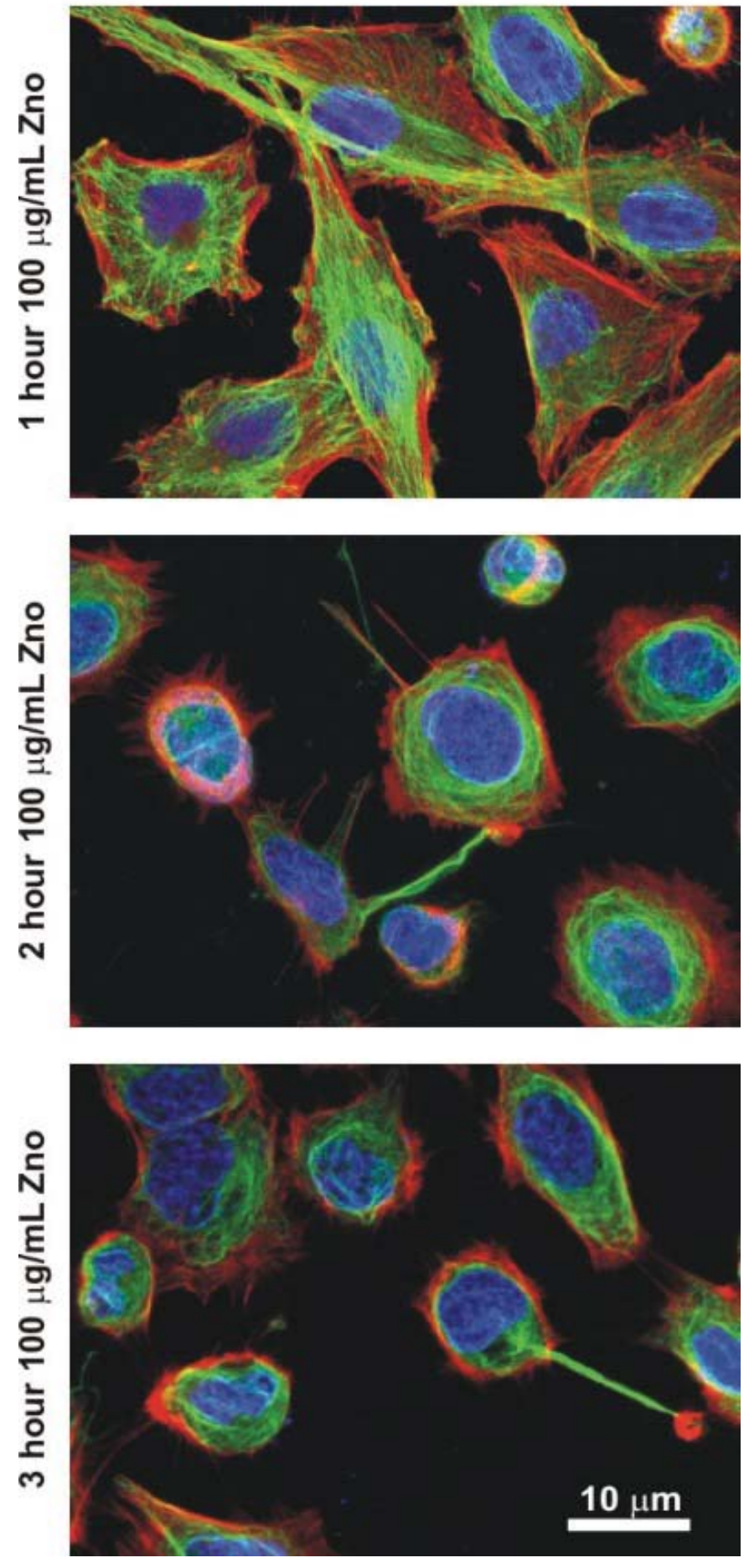

Figure S 5: Confocal microscopy images of cells exposed $\mathrm{ZnO}$ for the indicated times. These figures are high-resolution individual time points that complement those at Fig. 4. Aberrations in the organization of the actin microfilaments (red channel) and microtubules (green channel) progressively increase during exposure to $100 \mu \mathrm{g} / \mathrm{mL} \mathrm{ZnO}$ nanoparticles. 


\section{Supplementary Figure 6}

A
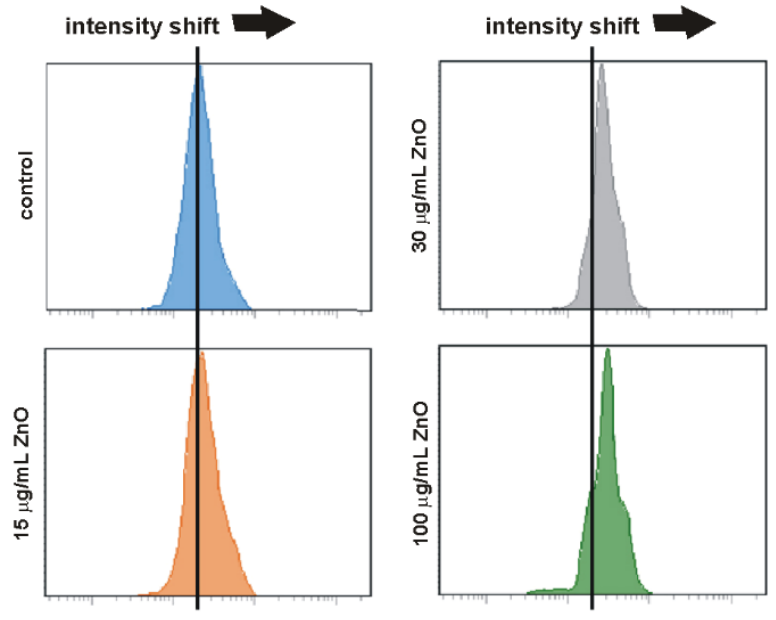

B
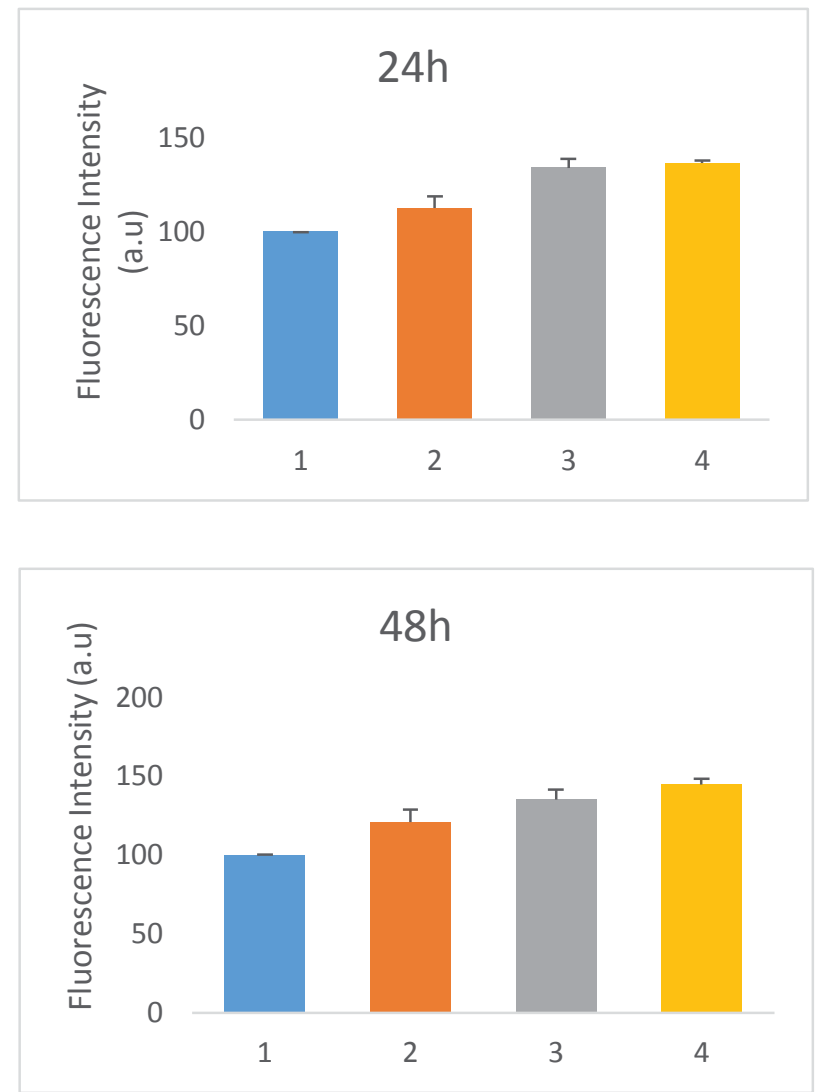

Figure S 6: ROS quantification in nano-ZnO exposed cells. (A) Intensity shift, representing the fluorescence levels per cell indicative of the intracellular ROS levels ( $24 \mathrm{~h}$ ) quantified by Flow cytometric analysis. The amount of ROS per cell is represented in the $X$ axis, and the total number of cells in the $Y$ axis. Each histogram chart represent the lecture in approximately 10.000 cells. (B) Simplified graphs as histograms representing the intracellular ROS levels for cells exposed to the indicated amounts of $\mathrm{ZnO}$ NPs during 24 and $48 \mathrm{~h}$ (Error bars obtained for 3 replicates). 